\title{
Prevalence and associated factors of cervical cancer among women in Ethiopia: A systematic review and meta-analysis
}

Dereje Zena Asrat ( $\sim$ derejezena@gmail.com )

Family Guidance Association of Ethiopia https://orcid.org/0000-0002-4418-8899

Berhanu Elfu Feleke

Bahir Dar University

Kebadnew Mulatu Mihretie

Bahir Dar University

Research article

Keywords:

Posted Date: December 27th, 2019

DOI: https://doi.org/10.21203/rs.2.19627/v1

License: (c) (1) This work is licensed under a Creative Commons Attribution 4.0 International License.

Read Full License 


\section{Abstract}

Background: cervical cancer is the second commonest disease of women in Ethiopia. Even though, some studies were conducted to assess the prevalence and associated factors of cervical cancer among women in Ethiopia, a variation in reported prevalence across the studies were observed. The aim of this study was to determine the pooled prevalence estimate and associated factors of cervical cancer among women in Ethiopia. Methodology: A systematic review and meta-analysis was performed based on published and gray literatures between 2010 and 2019. Articles were evaluated using Joanna Briggs Institute database guidelines by two independent authors. The pooled prevalence estimate was calculated using MedCalc software-version 19.0.7 and the pooled odd ratios for predictors was calculated using RevMan software version 5.3. A meta-analysis using a mantel Hansen variance randomeffects model was performed to assess the amount of variation in between studies. The report was depicted descriptively using pooled estimated prevalence and odd ratios using tables and plots. Result: From 124 retrieved data, 10 full text articles were eligible for the review. The pooled prevalence estimates of cervical cancer among women in Ethiopia using random-effect model was $15.7 \%, 95 \% \mathrm{Cl}(10.8,21.3 \%)$. Statistically significant heterogeneity between studies was detected $(\mathrm{I} 2=94.35 \%(p<0.0001)$. Among all associated factors measured: numbers of life time sexual partners $>1,0 R=0.40,95 \% \mathrm{Cl}(0.21,0.27)$, being HIV positive, $\mathrm{OR}=0.41,95 \% \mathrm{Cl}(0.21,0.75)$, having history of $\mathrm{STI}, \mathrm{OR}=1.99,95 \% \mathrm{Cl}(1.02,3.87)$, women getting widowed, separated or divorced), $\mathrm{OR}=0.32,95 \% \mathrm{Cl}(0.14,0.75)$, income $<1000 \mathrm{birr}, \mathrm{OR}=1.78,95 \% \mathrm{Cl}$ $(1.19,2.65)$ and women had experience of contraceptive use, $\mathrm{OR}=2.32,95 \% \mathrm{Cl}(1.75,3.43)$ were had statistical significant association with cervical cancer among women in Ethiopia Conclusion: The pooled prevalence estimate of cervical cancer among women in Ethiopia was high. There was a variation of cervical cancer reports across studies. Reporting of this information in a consistent manner is important for researchers to enhance future studies and also useful for policymakers and practitioners for better understanding of the burden of cervical cancer in Ethiopia for prevention, diagnosis, and early treatment of the disease. Trial registration: This systematic review for registration in PROSPERO was retrospectively registered on June 20,2019 .

\section{Introduction}

\subsection{Background}

Cervical cancer is stated as a major public health problem worldwide. Cervical cancer is a sexually transmitted disease caused by Human papillomavirus (HPV) commonly type 16 and 18 which cause $70 \%$ of cervical cancers and pre-cancerous cervical lesions (1).

Cervical pre-cancer goes through many stages and takes many years to develop into cervical cancer. It becomes cancer when the abnormal cells spread below the epithelial layer down into the deeper tissues of the cervix. In 2018 cervical cancer is estimated as the fourth most frequent cancer among leading causes of death for women worldwide. It represented $7.5 \%$ of all female cancers. More than $85 \%$ of these occur in less developed countries (1). 
According to the latest WHO data published in 2017 , cervical cancer accounts $0.78 \%$ of total deaths in Ethiopia. That is about 1 death due to cervical cancer of every 128 deaths, 14 people die of Cervical Cancer each day and an average of 1 death occurs every 2 hours(2).

Cervical cancer is preventable disease through periodic screening and early detection of lesions before progress to cancer. Precancerous lesions can be treated easily by cryotherapy using freezing gas (liquid nitrogen) to destroy precancerous cells on the cervix.

The most frequent method for cervical cancer screening is cytology, and there are alternative methods such as Human Papilloma Virus (HPV) Deoxyribonucleic Acid (DNA) tests and Visual Inspection with Acetic Acid (VIA). VIA is an alternative to cytology-based screenings in low resource settings. It is the 'see and treat' approach.

Low level of awareness, lack of effective screening programs, and lack of attention to women's health are the possible factors that leads to higher the prevalence rate of cervical cancers (13.4\%) in the Ethiopia. As a result, more than $80 \%$ of cervical cancer cases are detected at a late stage due to lack of information and weak preparedness to provide services(3).

Vaccines against HPV 16 and 18 are recommended by WHO and have been approved for use in many countries including Ethiopia(1).

The vaccine is widely administered in rich countries. While countries with the highest burden of cervical cancer in Africa and Asia are covering late (4).

Ethiopia launched Human Papilloma Virus (HPV) vaccination pilot project in December 2015 targeting adolescent girls in the 9-13 year age groups in Oromia and Tigray regions(3).

Cervical cancer can be cured if the infection is diagnosed and treated at an early stage (girls between the ages of 9 and 14 years) with the alignment of good life styles(4).

Some epidemiological studies are available to assess cervical cancer distribution and associated factors among women in Ethiopia. But individual studies show a wide variation of cervical cancer distribution over time and across geographical areas in the country. Therefore, the main objective of this systematic review and meta-analysis is to provide a pooled prevalence estimate and to assess associated factors of cervical cancer among women in Ethiopia in 2019 to answering the following research questions:

1. To what extent cervical cancer is distributed among women in Ethiopia?

2. What are the associated factors of cervical cancer among women in Ethiopia?

3. To what extent in-between variance among study reports on cervical cancer among women is observed in Ethiopia?

\subsection{Conceptual framework}


(Figure 1)

\section{Methods}

\subsection{Study settings}

Facility based studies done on cervical cancer among women in Ethiopian from 2010-2019 were used for this systemic review and meta-analysis project work. Ethiopia is one of the east African countries situated in the horn of Africa having a total population of $109,616,652$ and $50.2 \%$ of female population, 56.2 years (53.6-men, 58.8-women) of Life expectancy and $49.1 \%$ of Literacy. The land mark of Ethiopia covers an area of $1,104,300 \mathrm{KM}^{2}(36)$. The country has a federal system of governance with nine regional states and two chartered cities (32).

\subsection{Population, Intervention, comparator and Outcomes (PICOs)}

(Table 1)

\subsection{Searching strategy}

The presence of systemic review and meta-analysis on prevalence and associated factors of cervical cancer among women in Ethiopia was checked by searching different databases like: PubMed, Google scholar, Joanna Briggs Institute database (JBI), the national health center review and dissemination databases, and Prospero. There was no systematic review conducted on our topic of interest. Thus, to proceed this project work, the actual search was conducted from August 1 to 30,2019 by using different electronic databases like PubMed, Congress library, Medline(TR), Web science core collection for the published work and Google scholar for gray literature using Mesh terms "Prevalence OR Frequency OR Occurrence AND Risk Factors AND Cancer of Cervix OR Cancer of the Cervix OR Cervical OR Cancer of the Uterine Cervix OR Uterine Cervical Cancer OR Cervical Intraepithelial Neoplasia OR Cervical Cancer OR Cervix Cancer OR Cervical Neoplasms OR Uterine Cervical Neoplasms OR Cervix Neoplasms OR Neoplasms OR Cervix OR Uterine Cervical Cancer OR Tumor of the Uterine Cervix OR Uterine Cervical Dysplasia AND Girls OR Woman OR Women's Groups AND Human Papilloma Virus AND Ethiopia".

\subsection{Inclusion criteria}

The inclusion criteria for this study was

- Published and gray literatures with appropriate observational study designs conducted at health facility level on the prevalence and associated factors of cervical cancer among women in Ethiopia.

- Articles reported with English language, Odds Ratios (OR) and corresponding 95\% confidence intervals $(\mathrm{Cl})$. (Figure 2

\subsection{Data extraction (selection and coding)}


This systemic review and meta-analysis were performed based on published and gray literatures between 2010 and 2019. The retrieved data was screened independently by two reviewer authors (DZ and BE) to verify studies that possibly meet inclusion criteria. Any disagreement was resolved through discussion with a third reviewer (KM.). The third reviewer mediated any issues that remained unresolved. Data were extracted based on standardize data extraction tool adapted from JBI Meta-Analysis of Statistics Assessment and Review Instruments (MASARI)(37). Appropriate critical appraisal checklist of Observational Studies in Epidemiology (MOOSE) for systematic reviews (38)and the Preferred Reporting Items for Systematic Reviews and Meta-Analyses (PRISMA) statement for reporting systematic reviews and meta-analyses were used to assess the overall methodological quality of included studies(39). Each study data was extracted following year of publication, women demographics and baseline characteristics, study setting, number of cases enrolled, study population, study designs, prevalence and associated factors of cervical cancer. The two authors were extract the data from included studies independently and checked the retrieved data together. (Table $2 \&$ Table 3 )

\subsection{Risk of bias (quality) assessment}

Two review authors (DZ \& BE) were assessing the risk of bias independently before the retrieved articles were included using appropriate critical appraisal checklist of Observational Studies in Epidemiology (MOOSE). Moreover, the completeness of outcome data and other sources of bias were effectively assessed by the review authors (DZ\& BE) using Risk Of Bias In Non-randomized Studies of Interventions (ROBINS-I) detailed guidance to make domain-level judgements about risk of bias (40). Any disagreements between two review authors (DZ \& BE) were resolved by discussion and involvement of a third review author as mediator (KM). To minimize time-lag bias, the search was updated on August 30, 2019. Moreover, funnel plot was used to assess publication bias. During our study methodological quality assessment and scoring, one disagreement $(1 / 10)$ was happened between the primary (DZ) and secondary (BE) review authors. But the difference was resolved after discussion and involvement of the third researcher. Moreover, each study level cannot be considered comparable to a well-performed randomized trial. Therefore, there was a moderate risk of bias in this study.

\subsection{Strategy for data synthesis}

In total, 10 studies were eligible to conduct this study, but not all researchers had used the same classification for each predictor at their study level. When this kind of event happened, a better inclusive classification system or category was selected. But for age categories, midpoint calculation was employed to fit it in the best placement. If all these efforts did not work, studies containing unfitted categories for predictors would not be included in the study. Therefore, 6 full text cross-sectional studies, 1 comparative cross- sectional study and 3 case control studies conducted at health facility level among women in Ethiopia reported from 2010 to 2019 were used. Only 7 studies were used to measure the prevalence of cervical cancer screened by any methods whereas all eligible studies ( 10 full text articles) were chosen to measure associated factors of cervical cancer among women in Ethiopia. 


\subsection{Data analysis}

For this study, $2 \times 2$ tables summarizing was computed for each outcome measure. We also calculated a weighted study effect using a random effects model in case of heterogeneity at $P \leq 0.10$ for $\chi^{2}$ test during meta-analysis. The pooled prevalence estimate was calculated using MedCalc software-version 19.0.7 whereas the overall effects estimate of odd ratios for associated factors were calculated using RevMan software version 5.3.(41). The variance of the study was stabilized with Mantel Hensel before pooling the data within a random-effects or fixed effect meta-analysis model (42). In addition to these, Funnel plot was used to assess the presence of publication bias (43).Moreover, heterogeneity was evaluated by using the $\chi^{2}$ test and $\mathrm{I}^{2}$ value(44).

\section{Result}

\subsection{The pooled prevalence estimate of cervical cancer among women in Ethiopia}

Seven studies conducted at health facility level with a total simple size of 3951 were included to compute the pooled prevalence estimate of cervical cancer among women in Ethiopia. The highest prevalence was observed in a study done in gynecology referral Clinics in 2018 (39.5\%) (45) whereas the lowest point estimate was observed at a study conducted in North Ethiopia in 2017(6.7\%)(25). A Statistically significant heterogeneity between studies was also detected $\left(I^{2}=94.35 \%(p<0.0001)(\right.$ Table 4$)$.

This study based meta-analysis forest plot with random effects model discovered that more weight was given for a study conducted in Yirgalem General Hospital in 2017(19) (i.e. the bigger the box, the more participants in the study, the smaller $95 \%$ confidence intervals and the higher the precision to predict the pooled estimate).As a result, studies given the higher weights were had the more influence on the pooled effect estimate. Therefore; the combined point estimate of cervical cancer was found to be $15.7 \%, 95 \% \mathrm{Cl}$ $(10.78 \%, 21.31 \%)$ (Figure 3)

In figure 4, publication bias had been indicated by funnel plot symmetry or asymmetry. This visual inspection of the funnel plot confirmed that the plot was somewhat symmetrical. This indicates that there was no possible publication bias up on discovering the prevalence of cervical cancer among women in Ethiopia.

\subsection{Factors associated with cervical cancer among women in Ethiopia}

(Table 5 \&: Table 6)

At a meta-analysis level, each study was not given equal weighting in the comparison. Those studies with wider confidence intervals were given a lower weighting than those studies having narrow confidence intervals or those studies with a larger square were showing a higher weighting and vice versa. As a rule of thumb studies with a greater number of participants have a narrower confidence interval and a smaller horizontal line. That means the bigger the study, the smaller the horizontal line and the bigger the square 
of the point estimate or the smaller the study, the wider the horizontal line and smaller the square of the point estimate

A study conducted in gynecology clinics of Addis Ababa in 2019 (22) had more effect to pull the overall effect estimate to the left (favours to the bad event /cervical cancer). The $95 \% \mathrm{Cl}$ of this study did not overlap 1 (the no effect). So, there was statistical significance association with cervical cancer at the study level like a study conducted in Addis Ababa (46) and in Jimma (47). Both had the lowest effect on the overall effect estimate $(\mathrm{OR}=1.34,95 \% \mathrm{Cl}(0.56,3.12)$ respectively. More weight $(19.2 \%)$ was given for studies conducted in Addis Ababa (46) and in the Gurage zone (48). This tells us the weight was given based on the size of the sample they used for their studies.

Therefore, the overall effect estimates of women's age $(\mathrm{OR}=1.43,95 \% \mathrm{Cl}(0.65,3.12)$ was slightly associated with cervical cancer but it is not statistically supported (Figure 5).

From this sub group meta-analysis, the study done at Yirgalem General Hospital in 2017 had more effect size and weight on the combined effect estimate (19). Its $95 \%$ confidence interval did not overlap 1 (the no effect). The $95 \%$ confidence intervals of all other the studies overlap 1 . But the overall effect estimate $95 \% \mathrm{Cl}$ did not the no effect line That means marital status had statistically significant association with cervical cancer (Figure 6).

Except one study(19), all other studies did not show a statistically significant association with cervical cancer at a study level $(22,46,49)$. As a result, the overall effect estimate touches the line of no effect (Figure 7).

The study conducted at Yirgalem General Hospital in 2017 had more effect, high precision and statistically significant (19). But a study conducted in Addis Ababa in 2018 had low precision and statistically significant at a study level (22). Due to the higher weight (35.8\%) and more effect was given for a study done at Yirgalem General Hospital, it pulls the overall effect estimate towards to the better event (favours to Negative)(19). Moreover, studies were had higher heterogeneity $\left(I^{2}=96 \%\right)$ at $(p<0001)$. The $95 \% \mathrm{Cl}$ of the overall effect estimate did overlap the no effect line. That means there was no statistical significance (Figure 8).

In this analysis more effect was observed at a study conducted in Jimma University Specialized Hospital in 2015(47) where as more weight (52.7\%) was given for a study conducted at Yirgalem General Hospital in,2017 due to its larger simple size (19). Higher heterogeneity was also observed $\left(I^{2}=92 \%\right)$ between these studies. However, the combined effect estimate, $\mathrm{OR}=1.44,95 \% \mathrm{Cl}(0.37,5.58)$ did not show statistical significance (Figure 9).

Income was another important variable to predict cervical cancer distribution among women in Ethiopia. The $95 \%$ confidence intervals of all the studies did not overlap 1 and the $95 \%$ confidence intervals of the overall effect estimate did not overlap 1 . This indicates that there was statistical significance at the study level (Figure 10). 
As the forest plot indicates that the combined point estimate did not touch the null value. Therefore, there was statistically significant effect difference on cervical cancer between women of modern contraceptive users and non-users (Figure11).

All studies except a study done at Family Guidance Association of Ethiopia in Jimma in 2015(50), the $95 \%$ confidence intervals did not touch the line of no effect $(46,47,49)$. As a result, their effect pulled the overall effect estimate towards the left (bad event/cervical cancer episode). Thus, there was a statistically significant effect difference on cervical cancer prevalence between women having $>1$ life time sexual partners and women had 1 life time sexual partner $(\mathrm{OR}=0.40,95 \% \mathrm{Cl}(021,0.75)$ (Figure 12).

Like other variables history of STI predicted the prevalence of cervical cancer among women in Ethiopia. The overall effect estimate, $\mathrm{OR}=1.99,95 \% \mathrm{Cl}(1.02,3.87)$ showed that there was statistical significance effect difference between women having a history of STI and women did not have a history of STI (Figure 13).

This forest plot shows that the highest effect but the least weight (7.4\%) was given for a study done in North Ethiopia in 2016 even though it did not show statistical significance(25). The $95 \%$ confidence intervals of studies conducted at Debre Markos referral hospital, Addis Ababa and Yirgalem General Hospital did not overlap $1(19,46,51)$. But there was statistical significance effect difference at the metaanalysis level (Figure 14).

All studies $(22,46,47,50)$ except studies done in the Gurage zone(48) and Adama town(49), the $95 \%$ Cls cross the no effect line (1). Similarly, the combined effect estimate (the diamond) also overlaps on the no effect line (Figure 15).

This forest plot shows that the $95 \%$ confidence intervals of both studies $(46,47)$ overlap 1 as a result the $95 \%$ confidence intervals of the overall effect estimate also overlaps 1 (Figure 16).

\section{Discussion}

Cervical cancer is a major problem that threaten the developing countries which in fact the second commonest disease of women in Ethiopia (2). As a result, it remains a central issue for most researchers

Our study was the first systemic review aimed to combine the findings of primary studies to generate better estimated evidences on the prevalence and associated factors of cervical cancer among women in Ethiopia. To conduct this study a total of 10 eligible studies were included.

It was performed based on the guidelines outlined in the Preferred Reporting Items for Systematic Reviews and Meta-Analyses (PRISMA) (annex 9.5). Two investigators were verifying studies that possibly meet inclusion criteria and assessing the risk of bias for each eligible study independently. Any disagreement was resolved through discussion with a third reviewer author. 
Determining of the pooled prevalence estimate, the overall effect estimates for associated factors, assessment of heterogeneity between studies and the presence of publication bias were our central focus for this study

Therefore, the pooled prevalence estimate of cervical cancer among women in Ethiopia was (15.7\%). The highest prevalence was observed in a study done in gynecology referral Clinics in 2018 (39.5\%) (45) whereas the lowest point estimate was observed at a study conducted in North Ethiopia in 2017(6.7\%) (25). This pooled prevalence estimate was comparable with the pooled prevalence estimate conducted in china (15.54\%)(10)and Latin America (16.1\%)(7). But it was lower than the study conducted in Sudan (24\%)(15) and higher than studies conducted in Egypt (10.4\%)(13) and Qatari (8.1\%)(11). These differences might be due to socio-economic and cultural variations.

A Statistically significant heterogeneity between studies was also detected $(12=94.35 \%(p<0.0001)$. This might show that studies were inconsistent due to a reason other than chance (Table 4).

There was a variation of evidences reported on the effect of associated factors on cervical cancer like: women's age, education, occupation, residence and age at first sexual intercourse. Some studies revealed that they had a statistically significant association with cervical cancer while others did not show at their study levels (Figure 6,8,9,10,16 \& 17). This might be due to difference in sample size, variance, methodology, study populations and reliability of the outcome measures at each study level.

The overall effect estimates of women's age $(\mathrm{OR}=1.43,95 \% \mathrm{Cl}(0.65,3.12)$ was slightly associated with cervical cancer but it is not statistically supported. This indicate that we did not have enough evidence to say women of $\geq 40$ years were 1.34 times to have an effect of getting cervical cancer than women $<40$ years of age (Figure 5).

The odd of cervical cancer was $68 \%$ lower among married, widowed and divorced women than single women. It might be that all single women were not protected them from the risk of cervical cancer infection (Figure 6).

There was no overall effect difference association with cervical cancer between non formal educated and literate women (Figure 7) as women residing Urban and rural (Figure 9), women had first sexual intercourse at $<15$ years and $\geq 15$ years (Figure 15) and women ever had cervical cancer screening and women did not ever have cervical cancer screening (Figure 16).

Being unemployed women did not have clear difference effect on cervical cancer as compared to employed women (Figure 8).

Less episodes of cervical cancer were observed among women who did not have an experience of using modern contraceptives than users (Figure11). But more episode of cervical cancer was observed among women having $>1$ life time sexual partners than women had 1 life time sexual partner (Figure 12) 
The better outcome of cervical cancer was observed among women who did not have a history of STI than women having a history of STI (Figure 13).

Moreover, cervical cancer occurred less frequently among HIV negative women than HIV positive women $(\mathrm{OR}<1)$ (Figure 14).

\section{Limitation Of The Study}

This study was not done without limitations. When we describe some limitations, we hope that no one be considered them as inherently bad rather, they are good for readers, researchers and others to understand where new efforts need to be made or researchers may be inspired by these limitations and consider them as the foundation for their future studies. Therefore, some of the limitations of this study are failure to show sub group analysis due to small number of studies were included. Even if our study has strong design and estimable statistics, it may not be able to collect the most important missing data at a study level that might produce limitations in terms of interpreting the findings.

\section{Conclusion:}

The pooled prevalence estimate of cervical cancer among women in Ethiopia was high. The pooled prevalence estimate was had a statistical significance association with some variables like income, being HIV positive, previous STI history, more than one numbers of life time sexual partners and prolonged uses of modern contraceptives. There was also a variation of cervical cancer reports across studies. Reporting of this information in a consistent manner is important for researchers to enhance future studies and also useful for policymakers and practitioners for better understanding of the burden of cervical cancer in Ethiopia for prevention, diagnosis, and treatment of the disease.

\section{List Of Abbreviations}

AJOL-_-_-African Journal Online

BMC----BioMed Central

DNA-—-Deoxyribonucleic Acid

HIV--_---Human Immunodeficiency Virus

HPV_-_-Human Papilloma Virus

JBI-_-_-_Joanna Briggs Institute database

MASARI---Meta-Analysis of Statistics Assessment and Review Instruments

MEDLINE---Medical Literature Analysis and Retrieval System Online 
MOOSE---Methods of Observational Studies in Epidemiology

Popline---Population Information Online

PRISMA---Preferred Reporting Items for Systematic Reviews and Meta-Analyses

PubMed---Public Medicine

RevMan---Revie Manager

ROBINS-I --Risk Of Bias In Non-randomized Studies of Interventions

SNNPR---Southern Nations Nationalities and People Region

SSA-_-_-Sub-Saharan Africa

STI-_-_-_Sexual Transmitted Infection

VIA-_-_--Visual Inspection with Acetic acid

WHO_-_-World Health Organization

WWW---World Wide Web

\section{Declarations}

Ethics approval and consent to participate

Ethical clearance and permission were obtained from Bahir Dar University through a formal Letter.

Consent for publication

Not applicable

\section{Availability of data and materials}

This research data is available at the hand of the corresponding Author.

Dereje Zena

Email: derejezena@gmail.com

\section{Competing interests}

We declare that we have no competing interests.

\section{Funding}


No funding was given to support this study

\section{Authors' contributions}

The corresponding author (DZ) was involved in the conception, design, drafted the manuscript and data analysis of the study. All authors (DZ, BE\&KM) were involved in analysis and interpretation of data. All authors (DZ, BE\&KM) have been involved in critically revising the article for important intellectual content and have given final approval to the version to be published. All authors (DZ, BE\&KM) have read and approved the manuscript

\section{Acknowledgements}

Firstly, we would like to thank University of Bahir Dar College of Medicine and Health Sciences School of Public Health Department of Biostatistics and Epidemiology for providing this opportunity for us.

Secondly, our appreciation goes to all primary researchers who contributed their efforts to determine the prevalence and associated factors of cervical cancer among women in Ethiopia.

\section{References}

1. Human papillomavirus (HPV) and cervical cancer fact sheet 2019 [Available from: https://www.who.int/news-room/fact-sheets/detail/ human-papilloma virus-(hpv)-and-cervicalcancer.

2. Cervical Cancer in Ethiopia 2017 [Available from: http://causes of deathin.com/cervical-cancer-inEthiopia/

3. Ethiopia Launchs a Pilot Human Papilloma Virus Vaccination Project.

4. Ferlay J, Ervik M, Lam F, Colombet M, Mery L, Piñeros M, et al. Global cancer observatory: cancer today. Lyon, France: International Agency for Research on Cancer. 2018.

5. Birhanu Z AA, Belachew T, Deribew A, Segni H, Tsu V, et al. Health seeking behavior for cervical cancer in Ethiopia. International journal for Equity in health. 2012;11(1):83.

6. Athinarayanan S, Srinath M, Kavitha R. Detection and Classification of Cervical Cancer in Pap Smear Images using EETCM, EEETCM \& CFE methods-based Texture features and Various Classification Techniques. IJSRSET; 2016.

7. Bruni L, Diaz M, Castellsagué M, Ferrer E, Bosch FX, de Sanjosé S. Cervical Human Papillomavirus Prevalence in 5 Continents: Meta-Analysis of 1 Million Women with Normal Cytological Findings. The Journal of Infectious Diseases. 2010;202(12):1789-99.

8. Ahmad A. Cervical cancer statistics and Facts [updated September 13, 2018. Available from: https://www.diseasefix.com/page/cervical-cancer-statistics-and-facts/4622/.

9. De Vuyst H CG, Li N, Franceschi S. HPV infection in Europe. European journal of cancer. 2009;45(15):2632-9. 
10. Piao BZYLTZXCMLJZHYH. The prevalence, trends, and geographical distribution of human papillomavirus infection in China. Cancer Medicine. 2019.

11. Elmi AA, Bansal D, Acharya A, Skariah S, Dargham SR, Abu-Raddad LJ, et al. Human papillomavirus (HPV) infection: molecular epidemiology, genotyping, seroprevalence and associated risk factors among Arab women in Qatar. PloS one. 2017;12(1): e0169197.

12. Smith JS MA, Rana RK, Pimenta JM. Age-specific prevalence of infection with human papillomavirus in females: a global review. Journal of Adolescent Health. 2008;43(4): Journal of Adolescent Health.

13. Shaltout MF, etal. Prevalence and type distribution of human papillomavirus among women older than 18 years in Egypt: a multicenter. International Journal of Infectious Diseases. 2014;29 226-31.

14. Donkoh ET, Ph.D., *; Agyemang-Yeboah, Francis, MIBMS, PhD, MSc, BSc (Hons), LLB BL(GSL)b; Asmah, Richard Harry, DPhilc; Wiredu, Edwin K., MB ChB, MRCPath FWACP, FRCPath, FGCPSd. Prevalence of cervical cancer and pre-cancerous lesions among unscreened Women in Kumasi, Ghana. FGCPSdMedicine. 2019;98(13).

15. Shammat IM MZ, Alnayal MD, Elsadig M. Direct visual inspection of the cervix with acetic acid for the detection of premalignant lesions. Sudan Medical Laboratory Journal. 2015;2(2).

16. Cervical Cancer in Ethiopia 2017 [Available from: http://causes of deathin.com/cervical-cancer-inEthiopia/.

17. Mulisa Z AF, Assefa H. Prevalence and factors associated with VIA positive result among clients screened at Family Guidance Association of Ethiopia, south west area office, Jimma model clinic, Jimma, Ethiopia BMC Rsearch Notes. 2013; 8:618.

18. Getinet M, Gelaw, B., Sisay, A., Mahmoud, E. A., \& Assefa, A. Prevalence and predictors of Pap smear cervical epithelial cell abnormality among HIV-positive and negative women attending gynecological examination in cervical cancer screening center at Debre Markos referral hospital, East Gojjam, Northwest Ethiopia. BMC Clinical Pathology. 2015;15(16).

19. Hailemariam T, Yohannes B, Aschenaki H, Mamaye E, Orkaido G, Seta M. Prevalence of cervical Cancer and associated risk factors among women attending cervical Cancer screening and diagnosis Center at Yirgalem General Hospital, southern Ethiopia. J Cancer Sci Ther. 2017;9(11):7305.

20. Gedefaw A, Astatkie A, Tessema GA. The prevalence of precancerous cervical cancer lesion among HIV-infected women in southern Ethiopia: a cross-sectional study. PloS one. 2013;8(12): e84519.

21. Kassa LS, Dile WM, Zenebe GK, Berta AM. Precancerous lesions of cervix among women infected with HIV in Referral Hospitals of Amhara Region, Northwest Ethiopia: a cross sectional study. African health sciences. 2019;19(1):1695-704.

22. Ali KE, Mohammed IA, Difabachew MN, Demeke DS, Haile T, ten Hove R-J, etal. Burden and genotype distribution of high-risk Human Papillomavirus infection and cervical cytology abnormalities at selected obstetrics and gynecology clinics of Addis Ababa, Ethiopia. BMC cancer. 2019;19(1):1-9.

23. Sami-Ramzi Leyh-Bannurah CP, Maurits NC de Koning, Hartmut Goette and Ralph J Lellé Cervical human papillomavirus prevalence and genotype distribution among hybrid capture 2 positive women 
15 to 64 years of age in the Gurage zone, rural Ethiopia. Pubmed. 2014;9(1):33.

24. Dawit Wolday1, Muluken Derese2t, Solomon Gebressellassie2, Bekure Tsegaye1,6, Wondwossen Ergete3, Yirgu Gebrehiwot4, Orit Caplan5, Dana G. Wolf5 and Shlomo Maayan5. HPV genotype distribution among women with normal and abnormal cervical cytology presenting in a tertiary gynecology referral Clinic in Ethiopia. BMC. 2018; 13:28

25. Misgina KH, Belay HS, Abraha TH. Prevalence of precancerous cervical lesion and associated factors among women in North Ethiopia. Journal of Public Health and Epidemiology. 2017;9(3):46-50.

26. Butho BA, K. Jeremy, B. Patricia, and J. Paulina Factors associated with the uptake of cervical cancer screening among women in Portland Jamaica. North American Journal of Medical Sciences. 2015;7(3):104-13.

27. Gessesse Z TZ, Alemayehu M, Hiruye A, Getachew Y, Derbew M, etal. Determinant factors of visual inspection with acetic acid (VIA) positive lesions among HIV positive women in Mekelle Hospital, Northern Ethiopia. Ethiop Med J. 2015; 2:17-24.

28. Shimazu YSITTMMINSKMHIMNCNYKASKTATSTT. Research Group for the Development and Evaluation of Cancer Prevention Strategies in Japan Japanese Journal of Clinical Oncology. 2019;49(1):77-86.

29. Habtu Y, Yohannes S, Laelago T. Health seeking behavior and its determinants for cervical cancer among women of childbearing age in Hossana Town, Hadiya zone, Southern Ethiopia: community based cross sectional study. BMC cancer. 2018;18(1):298.

30. Frehiwot Getahun FM, Mulunesh Abuhayt and Zelalem Birhanut. Comprehensive knowledge about cervical cancer is low among women in Northwest Ethiopia. BMC Cancer. 2013;13(2).

31. Kabelenga Elijah ea. Determinants of Cervical Cancer Screening Uptake among Female Medical Students at the Copperbelt University, Micheal Chilufya Sata School of Medicine, Zambia. ARC Journal of Clinical. 2018;4(3):7-12.

32. Anorlu AAaRI. Knowledge of cervical cancer, awareness and attitude to screening among patients at a cytology clinic. Austin Journal of Obstetrics and Gynecology. 2014;1(1):4.

33. Hirut Teame LG, Tsega Kahsay, Kidanemaryam Berhe, Gdiom Gebreheat, Gebrehiwot Gebremariam. Factors affecting utilization of cervical cancer screening services among women attending public hospitals in Tigray region, Ethiopia. PLOS ONE. 2018;10.

34. Birhanu Z AA, Belachew T, Deribew A, Segni H, Tsu V et al. Health seeking behavior for cervical cancer in Ethiopia. Int J Equity Health. 2012; 11:83.

35. Birhanu Z, Abdissa A, Belachew T, Deribew A, Segni H, Tsu V, et al. Health seeking behavior for cervical cancer in Ethiopia: a qualitative study. International journal for Equity in health. 2012;11(1):83.

36. Population figures are estimates by Countrymeters (countrymeters.info) based on the latest United Nations data 2019 [Available from: http:/www.countrymeters.info.com.

37. Munn Z MS, Lisy K, Riitano D, Tufanaru C. Methodological guidance for systematic reviews of observational epidemiological studies reporting prevalence and incidence data. Int J Evid Based 
Healthc. $2015 ; 13: 147-53$.

38. Stroup DF B, Morton SC, Olkin I, Williamson GD, Rennie D, etal. Meta-analysis of observational studies in epidemiology. JAMA: the journal of the American Medical Association. 2000; 283:200812.

39. LiberatiA A, Tetzlaff J, Mulrow C, Gotzsche PC, loannidis JP, etal. The PRISMA statement for reporting systematic reviews and meta analyses of studies that evaluate healthcare interventions: explanation and elaboration. PLoSMed. 2009;6.

40. Schünemann HJ TP, Reeves BC, etal Non-randomized studies as a source of complementary, sequential or replacement evidence for randomized controlled trials in systematic reviews on the effects of interventions. Research Synthesis Methods. 2013;4.

41. (RevMan): Version 5.1, Copenhagen: The Nordic Cochrane Centre, the Cochrane Collaboration [Internet]. 2011.

42. Barendregt JJ DS, Lee YY, Norman RE, Vos T. Meta-analysis of prevalence. J Epidemiol Commun Health. 2013;67(11):4-8.

43. Egger M DSG, Schneider M, Minder C. Bias in meta-analysis detected by a simple, graphical test. BMJ. 1997;315(7109):629-34.

44. C. The combination of estimates from different experiments. Biometrics 1954;10(1):101-29.

45. Dawit Wolday1, Muluken Derese2†, Solomon Gebressellassie2, Bekure Tsegaye1,6, Wondwossen Ergete3, Yirgu Gebrehiwot4, Orit Caplan5, Dana G. Wolf5 and Shlomo Maayan5. HPV genotype distribution among women with normal and abnormal cervical cytology presenting in a tertiary gynecology referral Clinic in Ethiopia. BMC cancer. 2018; 13:28.

46. Teame H, Addissie A, Ayele W, Hirpa S, Gebremariam A, Gebreheat G, et al. Factors associated with cervical precancerous lesions among women screened for cervical cancer in Addis Ababa, Ethiopia: A case control study. PloS one. 2018;13(1): e0191506.

47. Bezabih M, Tessema F, Sengi H, Deribew A. Risk factors associated with invasive cervical carcinoma among women attending Jimma University Specialized Hospital, Southwest Ethiopia: A case control study. Ethiopian journal of health sciences. 2015;25(4):345-52.

48. Leyh-Bannurah S-R, Prugger C, de Koning MN, Goette H, Lellé RJ. Cervical human papillomavirus prevalence and genotype distribution among hybrid capture 2 positive women 15 to 64 years of age in the Gurage zone, rural Ethiopia. Infectious agents and cancer. 2014;9(1):33.

49. Kassa RT. Risk factors associated with precancerous cervical lesion among women screened at Marie Stops Ethiopia, Adama town, Ethiopia 2017: a case control study. BMC research notes. 2018;11(1):145.

50. Deksissa ZM, Tesfamichael FA, Ferede HA. Prevalence and factors associated with VIA positive result among clients screened at Family Guidance Association of Ethiopia, south west area office, Jimma model clinic, Jimma, Ethiopia 2013: a cross-sectional study. BMC research notes. 2015;8(1):618. 
51. Getinet M, Gelaw B, Sisay A, Mahmoud EA, Assefa A. Prevalence and predictors of Pap smear cervical epithelial cell abnormality among HIV-positive and negative women attending gynecological examination in cervical cancer screening center at Debre Markos referral hospital, East Gojjam, Northwest Ethiopia. BMC clinical pathology. 2015;15(1):16.

\section{Tables}

\subsection{Population, Intervention, comparator and Outcomes (PICOs)}

Table 1: The Population, Intervention, Compotator and Outcomes (PICOs) for associated factors of cervical cancer among women in Ethiopia from $2010-2019$

\begin{tabular}{|c|c|c|c|}
\hline Intervention & comparator & Outcomes & Population \\
\hline Education & Primarily and above education & $\begin{array}{l}\text { Cervical } \\
\text { cancer } \\
\text { positive }\end{array}$ & $\begin{array}{l}\text { Women in } \\
\text { Ethiopia }\end{array}$ \\
\hline $\begin{array}{l}\text { Married, } \\
\text { Widowed }\end{array}$ & Single & $\begin{array}{l}\text { Cervical } \\
\text { cancer } \\
\text { positive }\end{array}$ & $\begin{array}{l}\text { Women in } \\
\text { Ethiopia }\end{array}$ \\
\hline $\begin{array}{l}\text { Women having } \\
\text { sexual partners }\end{array}$ & $\begin{array}{l}\text { Women did not have multiple } \\
\text { sexual partners }\end{array}$ & $\begin{array}{l}\text { Cervical } \\
\text { cancer } \\
\text { positive }\end{array}$ & $\begin{array}{l}\text { Women in } \\
\text { Ethiopia }\end{array}$ \\
\hline first intercourse $<15$ years & first intercourse $\geq 15$ years & $\begin{array}{l}\text { Cervical } \\
\text { cancer } \\
\text { positive }\end{array}$ & $\begin{array}{l}\text { Women in } \\
\text { Ethiopia }\end{array}$ \\
\hline $\begin{array}{l}\text { Women having previous } \\
\text { history of STI infection }\end{array}$ & $\begin{array}{l}\text { Women did not have previous } \\
\text { history of STI infection }\end{array}$ & $\begin{array}{l}\text { Cervical } \\
\text { cancer } \\
\text { positive }\end{array}$ & $\begin{array}{l}\text { Women in } \\
\text { Ethiopia }\end{array}$ \\
\hline
\end{tabular}

Table 2: Summary of eligible articles included to review the prevalence and associated factors of cervical cancer among women in in Ethiopia.

\begin{tabular}{|l|l|l|l|c|l|}
\hline No & ID & $\begin{array}{l}\text { Author name and } \\
\text { publication }\end{array}$ & Tittle of the study & $\begin{array}{l}\text { Study } \\
\text { design }\end{array}$ & $\begin{array}{l}\text { Overall } \\
\text { quality }\end{array}$ \\
\hline 1 & 10 & Mesele B. etal, 2015 & $\begin{array}{l}\text { Risk Factors Associated with Invasive Cervical } \\
\text { Carcinoma among Women Attending Jimma } \\
\text { University Specialized Hospital, Southwest } \\
\text { Ethiopia }\end{array}$ & $\begin{array}{c}\text { Case } \\
\text { control }\end{array}$ & $8 / 10$ \\
\hline 2 & 16 & Deksissa etal, 2015 & $\begin{array}{l}\text { Prevalence and factors associated with VIA } \\
\text { positive result among clients screened at Family } \\
\text { Guidance Association of Ethiopia, south west area } \\
\text { nffinn Timmn madnl nlinin Timmn Dthinnin nn1 2 }\end{array}$ & $\begin{array}{l}\text { Cross- } \\
\text { sectional }\end{array}$ & $7 / 9$ \\
\end{tabular}




\begin{tabular}{|c|c|c|c|c|c|}
\hline & & & 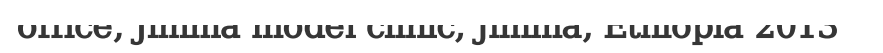 & & \\
\hline 3 & 35 & Getinet M. etal, 2015 & $\begin{array}{l}\text { Prevalence and predictors of Pap smear cervical } \\
\text { epithelial cell abnormality among HIV-positive } \\
\text { and negative women attending gynecological } \\
\text { examination in cervical cancer screening center } \\
\text { at Debre Markos referral hospital, East Gojjam, } \\
\text { Northwest Ethiopia }\end{array}$ & $\begin{array}{l}\text { Comparative } \\
\text { Cross- } \\
\text { sectional }\end{array}$ & $6 / 8$ \\
\hline 4 & 47 & Kassa R. 2018 & $\begin{array}{l}\text { Risk factors associated with precancerous } \\
\text { cervical lesion among women screened at Marie } \\
\text { Stops Ethiopia, Adama town, Ethiopia } 2017\end{array}$ & Case control & $8 / 10$ \\
\hline 5 & 50 & Leyh-B. etal, 2014 & $\begin{array}{l}\text { Cervical human papillomavirus prevalence and } \\
\text { genotype distribution among hybrid capture } 2 \\
\text { positive women } 15 \text { to } 64 \text { years of age in the } \\
\text { Gurage zone, rural Ethiopia }\end{array}$ & $\begin{array}{c}\text { Cross- } \\
\text { sectional }\end{array}$ & $7 / 8$ \\
\hline 6 & 61 & Gebreheat G. etal, 2018 & $\begin{array}{l}\text { Factors associated with cervical precancerous } \\
\text { lesions among women screened for cervical } \\
\text { cancer in Addis Ababa, Ethiopia }\end{array}$ & Case control & $8 / 10$ \\
\hline 7 & 64 & Wolday D. etal, 2018 & $\begin{array}{l}\text { HPV genotype distribution among women with } \\
\text { normal and abnormal cervical cytology presenting } \\
\text { in a tertiary gynecology referral Clinic in Ethiopia }\end{array}$ & $\begin{array}{l}\text { Cross- } \\
\text { sectional }\end{array}$ & $6 / 8$ \\
\hline 8 & 69 & HailemariamT.etal,2017 & $\begin{array}{l}\text { Prevalence of Cervical Cancer and Associated } \\
\text { Risk Factors among Women Attending Cervical } \\
\text { Cancer Screening and Diagnosis Center at } \\
\text { Yirgalem General Hospital, Southern Ethiopia }\end{array}$ & $\begin{array}{l}\text { Cross- } \\
\text { sectional }\end{array}$ & $7 / 9$ \\
\hline 9 & 76 & Misgina etal,2016 & $\begin{array}{l}\text { Prevalence of precancerous cervical lesion and } \\
\text { associated factors among women in North } \\
\text { Ethiopia }\end{array}$ & $\begin{array}{l}\text { Cross- } \\
\text { sectional }\end{array}$ & $7 / 9$ \\
\hline 10 & 85 & Ali etal, 2019 & $\begin{array}{l}\text { Burden and genotype distribution of high-risk } \\
\text { Human Papillomavirus infection and cervical } \\
\text { cytology abnormalities at selected obstetrics and } \\
\text { gynaecology clinics of Addis Ababa, Ethiopia }\end{array}$ & $\begin{array}{l}\text { Cross- } \\
\text { sectional }\end{array}$ & $7 / 9$ \\
\hline
\end{tabular}

Table 3: Summary of eligible articles included to review the prevalence and associated factors of cervical cancer among women in in Ethiopia.

\begin{tabular}{|c|c|c|c|c|c|}
\hline No & ID & $\begin{array}{l}\text { Author name and } \\
\text { publication }\end{array}$ & $\begin{array}{c}\text { Total } \\
\text { sample } \\
\text { size }\end{array}$ & Prevalence & $\begin{array}{c}\text { Statistically significant associated } \\
\text { factors }\end{array}$ \\
\hline 1 & 10 & Mesele B. etal, 2015 & $\begin{array}{c}180 \\
(60: 120)\end{array}$ & NA & $\begin{array}{l}\text { Women: } \\
\text { - 40-59 years, } \mathrm{AOR}=4.7 \& 95 \% \mathrm{CI}(2.3, \\
9.6) \\
\text { - Had }>1 \text { husband, } \mathrm{AOR}=2.0 ; 95 \% \mathrm{CI}(1.0 \text {, } \\
\text { 3.9) and }\end{array}$ \\
\hline
\end{tabular}




\begin{tabular}{|c|c|c|c|c|c|}
\hline & & & & & $\begin{array}{l}\text { Had }>4 \text { children, } \mathrm{AOR}=10.3,95 \% \mathrm{CI} \\
(3.6,29.0)\end{array}$ \\
\hline 2 & 16 & Deksissa etal, 2015 & 334 & $\begin{array}{c}43 \\
(12.9 \%)\end{array}$ & $\begin{array}{l}\text { Sexual intercourse }<16 \text { years, } \\
\mathrm{OR}=2.2,95 \% \mathrm{CI}(1.1,4.3)\end{array}$ \\
\hline 3 & 35 & Getinet M. etal, 2015 & 194 & $\begin{array}{c}55 \\
(14.0 \%)\end{array}$ & $\begin{array}{l}\text { - HIV+ women, AOR }=1.9,95 \% \mathrm{CI}(1.1 \text {, } \\
\text { 3.4) } \\
\text { Multiple sexual partnership, AOR =3.2, } \\
95 \% \text { CI }(1.1,10.0) \\
\text { - First sexual contact <15 years, AOR } \\
=5.2,95 \% \text { CI }(1.5,17.9) \text { and } \\
\text { - Long term oral contraceptive pills use, } \\
\text { AOR }=11.9,95 \% \text { CI }(2.1,16.7)\end{array}$ \\
\hline 4 & 47 & Kassa R. 2018 & $\begin{array}{c}164 \\
(55: 109)\end{array}$ & NA & $\begin{array}{l}\text { Use of oral contraception } \mathrm{OR}=2.342 \text {, } \\
95 \mathrm{CI}(1.1,4.9) \\
\text { History of STI, A OR= } 2.485,95 \mathrm{CI}(1.19 \\
5.2) \text { and } \\
\text { Age at1st sexual intercourse }<15 \text { years, } \\
\text { AOR }=6.70,95 \mathrm{CI} \%(1.73,10.12)\end{array}$ \\
\hline 5 & 50 & Leyh-B. etal, 2014 & 537 & $\begin{array}{c}86 \\
(16.1 \%)\end{array}$ & $\begin{array}{l}\text { Widowed AOR =1.85, } 95 \% \text { CI }(1.0,3.4) \\
\text { and } \\
\text { - Had >1 lifetime sexual partners AOR } \\
=1.83,95 \% \text { CI }(1.0,3.2)\end{array}$ \\
\hline 6 & 61 & Gebreheat G. etal, 2018 & $\begin{array}{c}343 \\
(114: 229)\end{array}$ & NA & $\begin{array}{l}\text { 40-49 years, AOR=2.55, 95\% CI }(1.5 \text {, } \\
4.2) \\
\text { having history STI AOR=3.20, 95\% CI } \\
(1.2,8.1) \text { and } \\
\text { had }>/=2 \text { lifetime sexual partners, } \\
\text { AOR=2.17, 95\% CI }(1.0,4.7)\end{array}$ \\
\hline 7 & 64 & Wolday D. etal, 2018 & 233 & $\begin{array}{c}92 \\
(39.5 \%)\end{array}$ & $\begin{array}{l}\text { - Of rural reside, } \mathrm{AOR}=6.89,95 \%(1.9 \text {, } \\
4.8 \text { ) and } \\
\text { had history of STI, AOR=2.72, } 95 \% \text { (1.4, } \\
5.2)\end{array}$ \\
\hline 8 & 69 & HailemariamT.etal,2017 & 1945 & $\begin{array}{c}32 \\
(16.5 \%) \\
\end{array}$ & 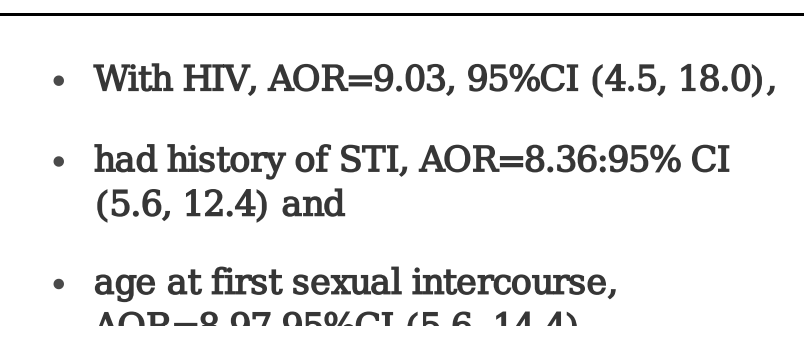 \\
\hline
\end{tabular}




\begin{tabular}{|c|c|c|c|c|c|}
\hline & & & & & AUR=0.J1,כJ Jou1 (U.U, 14.4) \\
\hline 9 & 76 & Misgina etal,2016 & 342 & $\begin{array}{c}23 \\
(6.7 \%)\end{array}$ & \\
\hline 10 & 85 & Ali etal, 2019 & 360 & $\begin{array}{c}50 \\
(13.7 \%)\end{array}$ & $\begin{array}{l}\text { Unemployed AOR=9.17, 95\%CI (1.6, } \\
52.2) \\
\text { - Positive AOR=5.73, 95\%CI }(1.1,30.9) \\
\text { and } \\
\text { - Resided out of Addis Ababa AOR=8.12, } \\
\text { 95\%CI }(1.1,57.9)\end{array}$ \\
\hline
\end{tabular}

Table 4: Eligible studies included to estimation the pooled prevalence of cervical cancer among women in Ethiopia

\begin{tabular}{|c|c|c|c|c|c|}
\hline \multicolumn{1}{|c|}{ Study } & Sample & Proportion (\%) & $95 \%$ CI & \multicolumn{2}{|c|}{ Weight (\%) } \\
\cline { 5 - 6 } & Size & & & Fixed & Random \\
\hline 1. Ali etal 2019 & 366 & 13.661 & $\begin{array}{c}10.31 \\
-17.61\end{array}$ & 9.27 & 14.34 \\
\hline 1. Deksissa etal 2015 & 334 & 12.874 & 9.48 & 8.46 & 14.24 \\
\hline 1. Getinet M etal 2015 & 194 & 10.309 & $6.41-$ & 4.93 & 13.49 \\
\hline 1. HailemariamT.etal & 1945 & 16.504 & 14.88 & 49.17 & 15.21 \\
2017 & & & -18.23 & & \\
\hline 1. Leyh B. etal 2014 & 537 & 16.015 & 13.01 & 13.59 & 14.67 \\
\hline 1. Misganaetal 2016 & 342 & 6.725 & $4.31-9.92$ & 8.67 & 14.27 \\
\hline 1. Wolday D. etal 2018 & 233 & 39.485 & 33.16 & 5.91 & 13.78 \\
\hline Total (fixed effects) & 3951 & 15.723 & 14.60 & 100.00 & 100.00 \\
& & & -16.89 & & \\
\hline Total (random effects) & 3951 & 15.686 & 10.78 & 100.00 & 100.00 \\
& & & -21.31 & & \\
\hline
\end{tabular}

\section{Test for heterogeneity}

\begin{tabular}{|l|l|}
\hline $\mathrm{Q}$ & 106.1961 \\
\hline $\mathrm{DF}$ & 6 \\
\hline Significance level & $\mathrm{P}<0.0001$
\end{tabular}




\begin{tabular}{|l|l|}
\hline I2 (inconsistency) & $94.35 \%$ \\
\hline $95 \%$ CI for I2 & 90.68 to 96.57 \\
\hline
\end{tabular}

\subsection{Factors associated with cervical cancer among women in Ethiopia}

Table 5: Socio-Demographic and other variables associated with cervical cancer among women in Ethiopia

\begin{tabular}{|c|c|c|c|c|}
\hline \multirow[b]{2}{*}{ Articles } & \multicolumn{2}{|c|}{ Experiment } & \multicolumn{2}{|c|}{ Control } \\
\hline & Positive & Total & \multirow{2}{*}{\multicolumn{2}{|c|}{\begin{tabular}{ll|l} 
Positive & Total \\
vs $<40$ years
\end{tabular}}} \\
\hline Age: $(n=6)$ & \multicolumn{2}{|c|}{$\geq 40$ years } & & \\
\hline 1. Ali etal, 2019 & 28 & 313 & 10 & 53 \\
\hline 1. Deksissa etal, 2015 & 2 & 22 & 41 & 308 \\
\hline 1. Gebreheat G. etal, 2018 & 70 & 154 & 43 & 188 \\
\hline 1. Kassa R. 2018 & 6 & 17 & 48 & 144 \\
\hline 1. Leyh B. etal, 2014 & 53 & 322 & 33 & 212 \\
\hline 1. Melese B. etal, 2015 & 44 & 80 & 16 & 100 \\
\hline Education: $(\mathrm{n}=3)$ & Non formal edu & ated vs & Literate & \\
\hline 1. Ali etal, 2019 & \begin{tabular}{l|l} 
& 1
\end{tabular} & 38 & 37 & 290 \\
\hline 1. HailemariamT.etal, 2017 & 28 & 40 & 76 & 289 \\
\hline 1. Kassa R. 2018 & 3 & 14 & 52 & 96 \\
\hline Marital status: $(n=3)$ & Married & $\mathrm{vS}$ & Sin & \\
\hline 1. Ali etal, 2019 & 28 & 287 & 7 & 32 \\
\hline 1. HailemariamT.etal, 2017 & 232 & 1459 & 45 & 89 \\
\hline 1. Misgina etal, 2016 & 19 & 233 & 4 & 109 \\
\hline Marital status: $(\mathrm{n}=2)$ & Divorced / wido & ed vs & Sing & \\
\hline 1. Ali etal, 2019 & \begin{tabular}{l|l} 
& 3
\end{tabular} & 47 & 7 & 32 \\
\hline
\end{tabular}




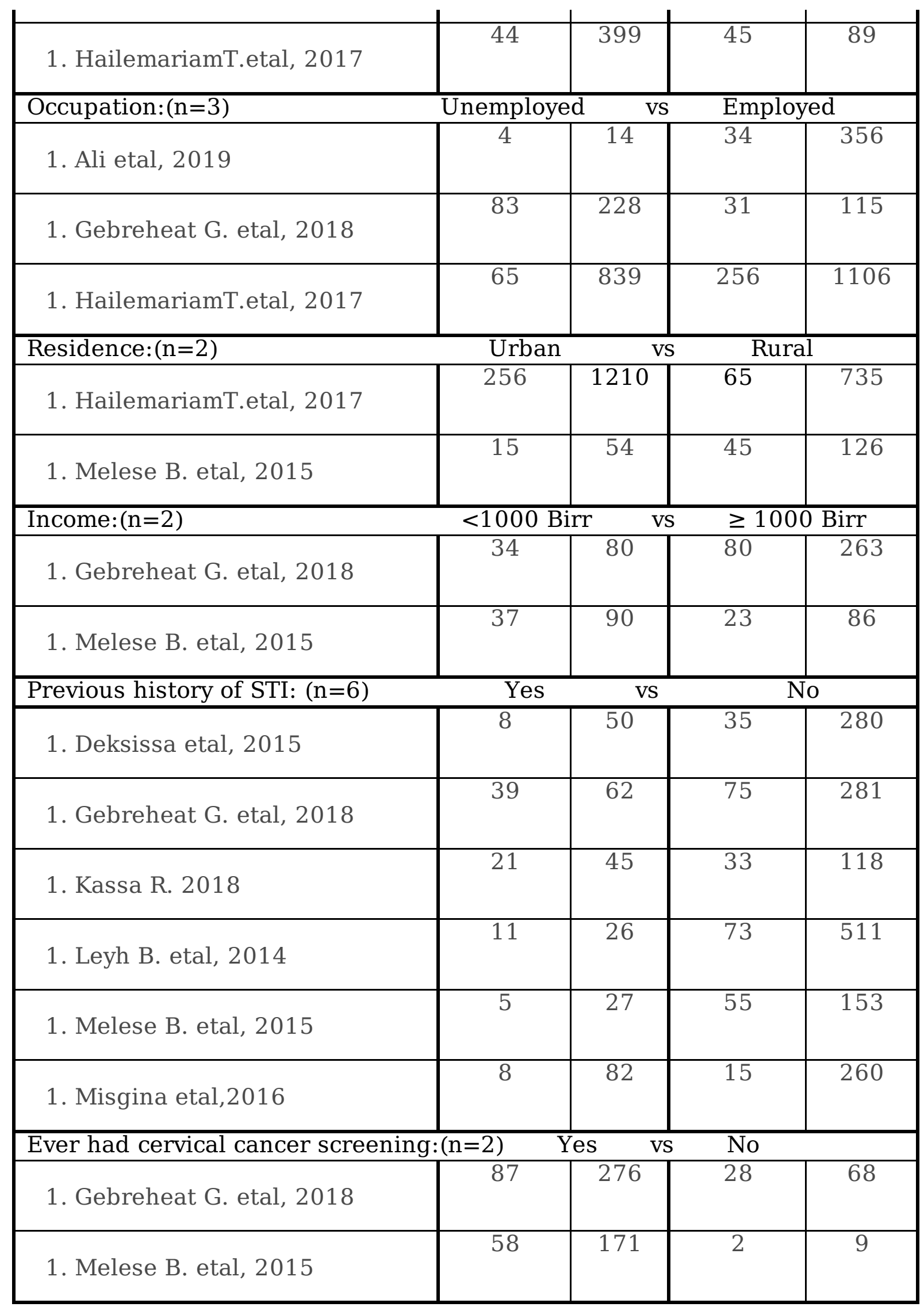

Table 6: Socio-Demographic and other variables associated with cervical cancer among women in Ethiopia (continued) 


\begin{tabular}{|l|c|c|c|c|}
\hline \multirow{2}{*}{ Articles } & \multicolumn{2}{|c|}{ Experiment } & \multicolumn{2}{c|}{ Control } \\
\cline { 2 - 5 } & Positive & Total & Positive & Total \\
\hline
\end{tabular}

\begin{tabular}{|c|c|c|c|c|}
\hline Ever use modern Contraceptives: $(\mathrm{n}=3)$ & $\mathrm{Y}$ & & & No \\
\hline 1. Deksissa etal, 2015 & 18 & 111 & 25 & 219 \\
\hline 1. HailemariamT.etal, 2017 & 274 & 1487 & 108 & 1477 \\
\hline 1. Kassa R. 2018 & 41 & 102 & 14 & 59 \\
\hline HIV status: $(n=6)$ & Positive & $\mathrm{vS}$ & & egative \\
\hline 1. Deksissa etal, 2015 & 21 & 134 & 20 & 168 \\
\hline 1. Gebreheat G. etal, 2018 & 46 & 99 & 67 & 240 \\
\hline 1. Getinet M. etal, 2015 & 35 & 181 & 20 & 194 \\
\hline 1. HailemariamT. Etal, 2017 & 39 & 65 & 282 & 1844 \\
\hline 1. Kassa R. 2018 & 9 & 18 & 33 & 67 \\
\hline 1. Misgina etal,2016 & 1 & 16 & 22 & 326 \\
\hline Age at 1st sexual intercourse: $(n=6)$ & $<15 \mathrm{y}$ & ar vs & $\geq$ & 15 years \\
\hline 1. Ali etal, 2019 & 2 & 39 & 38 & 327 \\
\hline 1. Deksissa etal, 2015 & 22 & 144 & 17 & 175 \\
\hline 1. Gebreheat G. etal, 2018 & 26 & 70 & 88 & 286 \\
\hline 1. Kassa R. 2018 & 25 & 45 & 30 & 119 \\
\hline 1. Leyh B. etal, 2014 & 55 & 414 & 31 & 123 \\
\hline 1. Melese B. etal, 2015 & 6 & 34 & 54 & 146 \\
\hline \multicolumn{2}{|l|}{ No of Life time sexual partners: $(n=4)$} & $>1$ & & 1 \\
\hline 1. Deksissa etal, 2015 & 32 & 241 & 11 & 89 \\
\hline & 43 & 202 & 71 & 141 \\
\hline
\end{tabular}




\begin{tabular}{|c|c|c|c|c|}
\hline 1. Kassa R. 2018 & 15 & 81 & 40 & 83 \\
\hline 1. Melese B. etal, 2015 & 36 & 128 & 24 & 49 \\
\hline
\end{tabular}

\section{Figures}

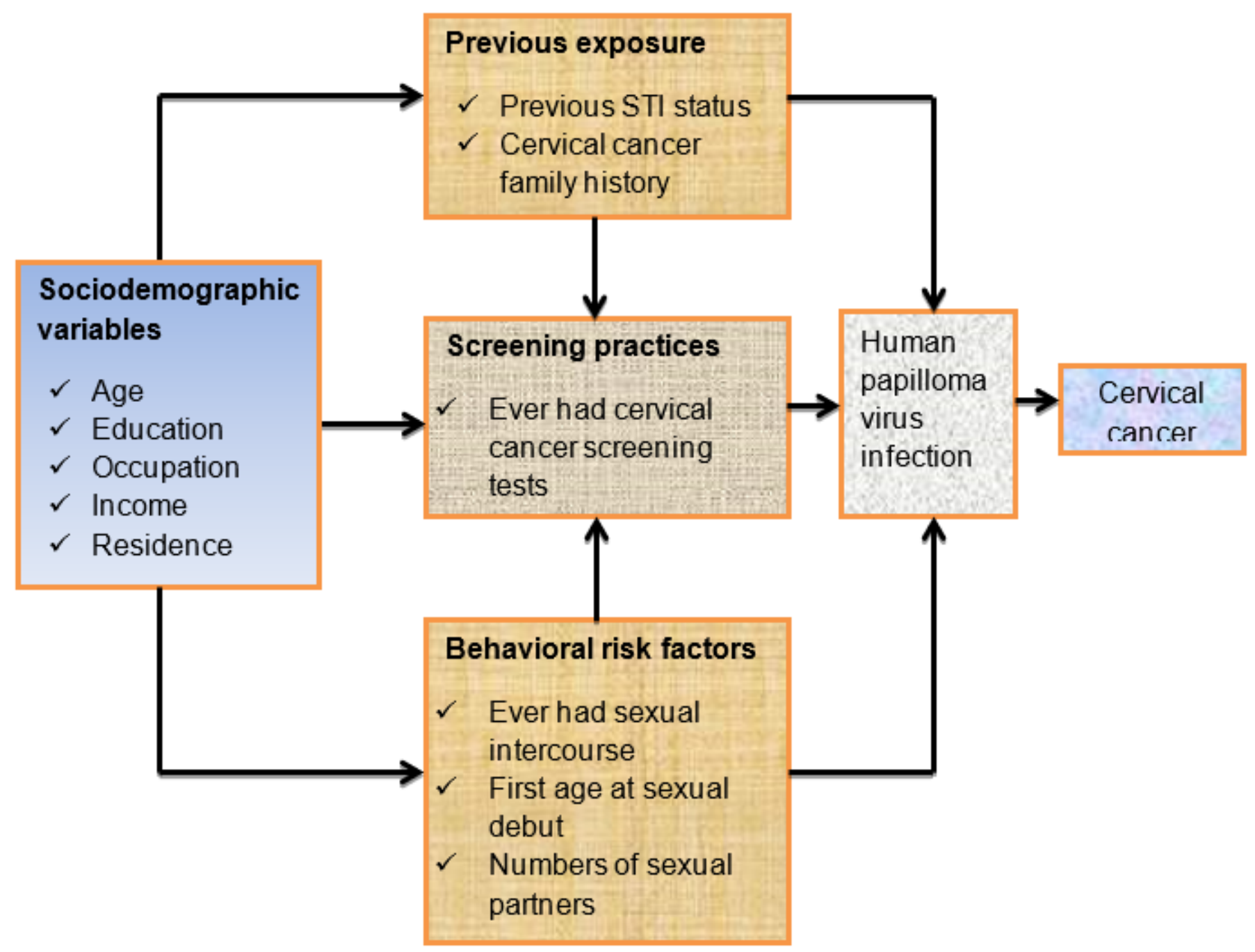

Figure 1

Conceptual framework showing determinants of cervical cancer among women in Ethiopia. 


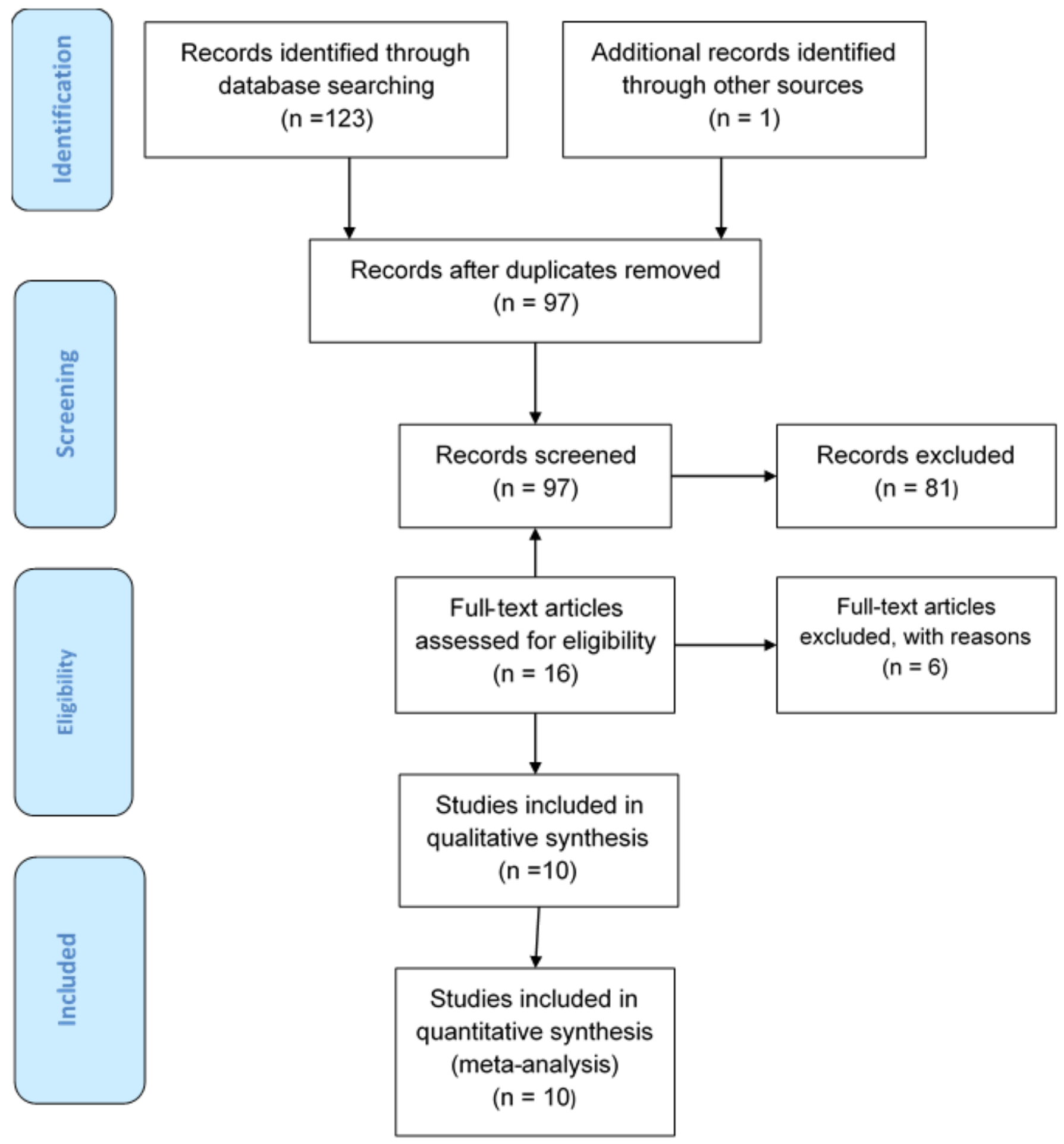

Figure 2

Flow diagram showing included and excluded articles to review the prevalence and associated factors of cervical cancer among women in Ethiopia. 


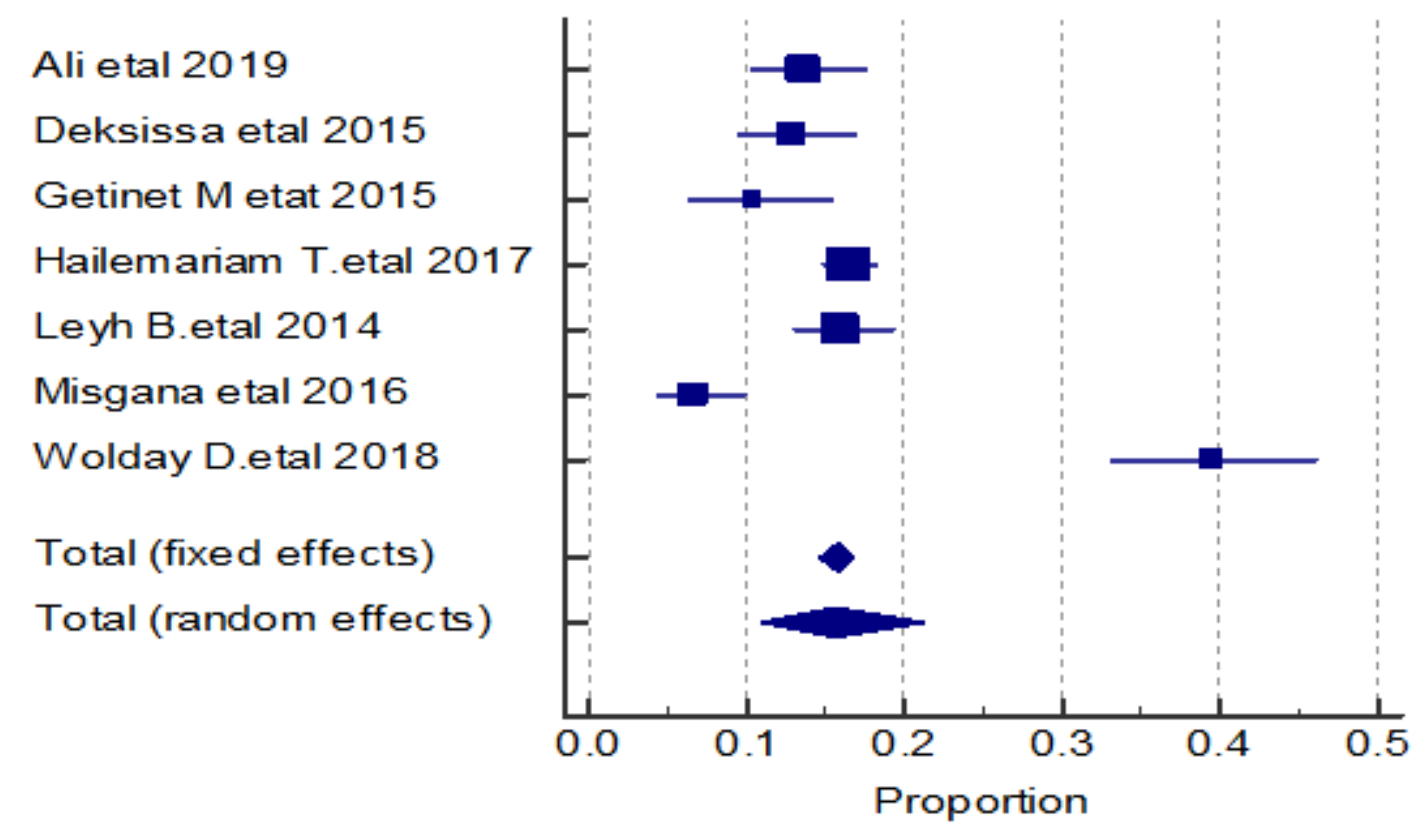

\section{Figure 3}

A forest plot showing the pooled prevalence of cervical cancer among women in Ethiopia.

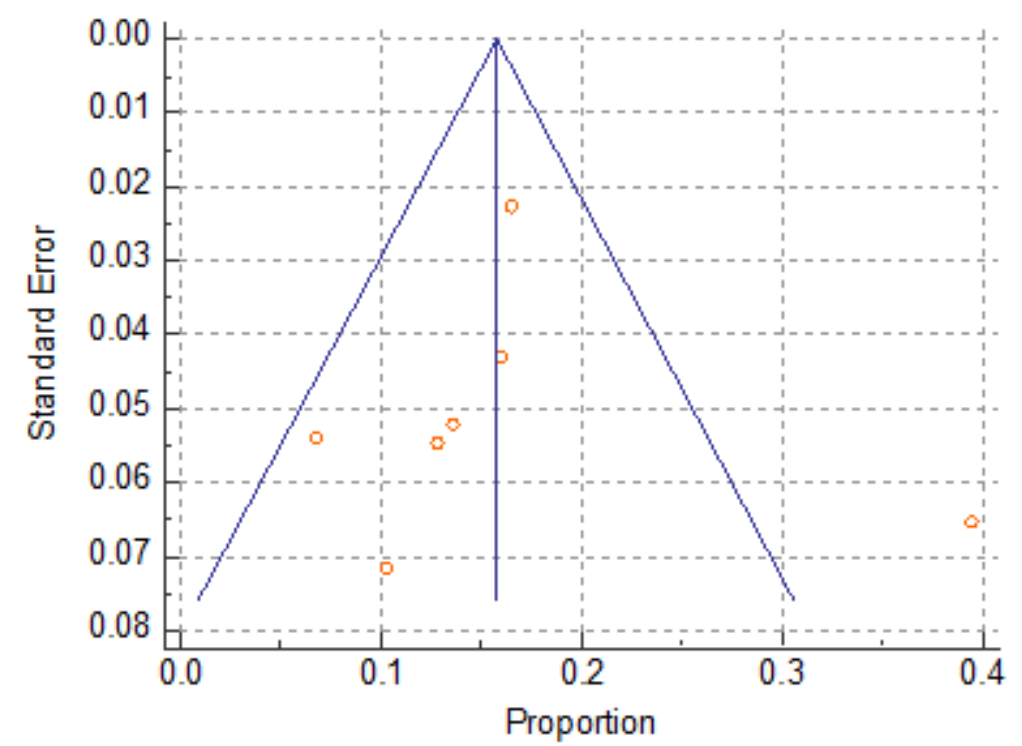

Figure 4

Funnel plot showing publication bias among studies conducted on prevalence of cervical cancer in Ethiopia 


\section{Y=40 years ¿40 years Odds Ratio Odds Ratio}

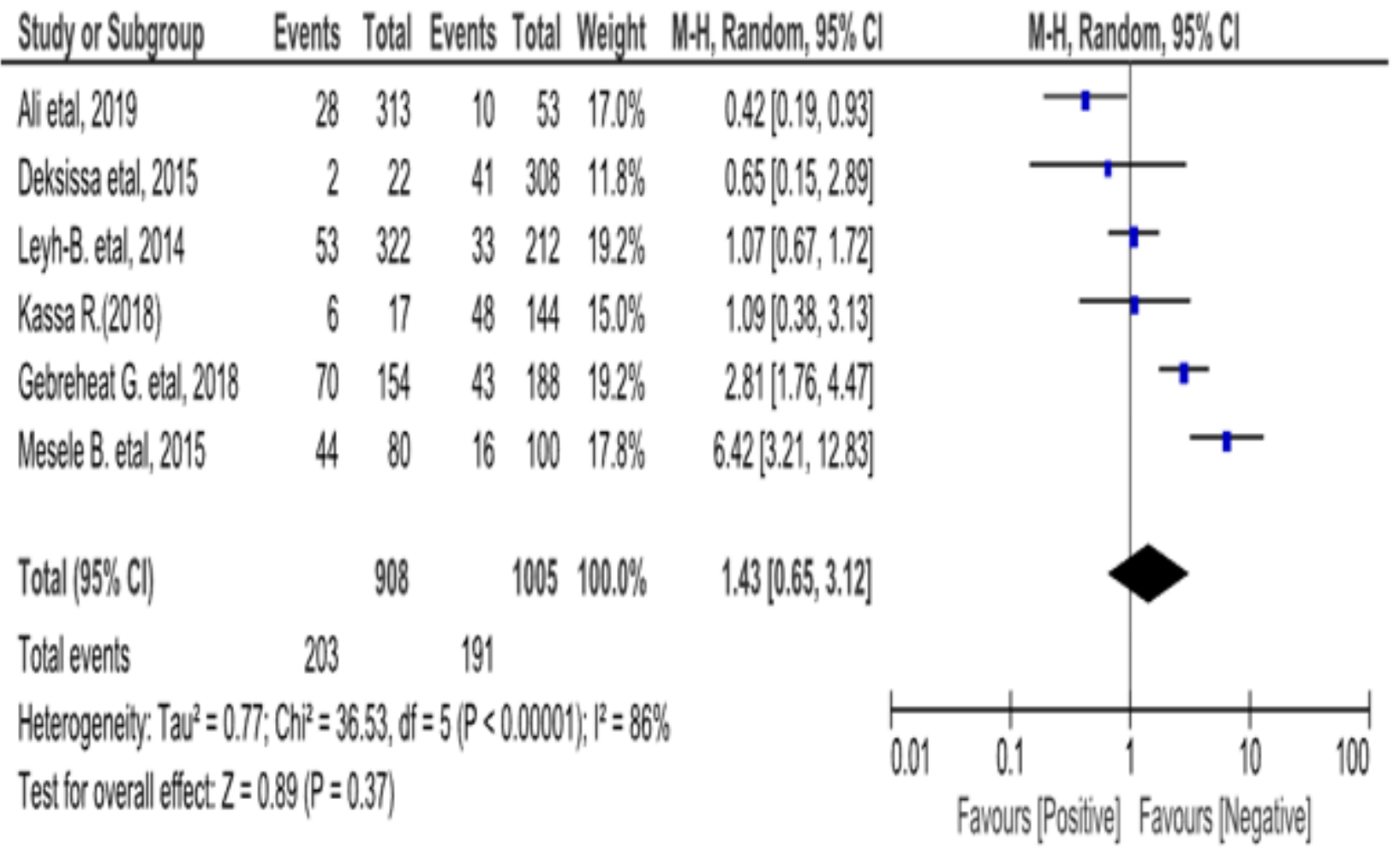

\section{Figure 5}

Forest plot showing the association between age and cervical cancer among women in Ethiopia $(n=6)$ 


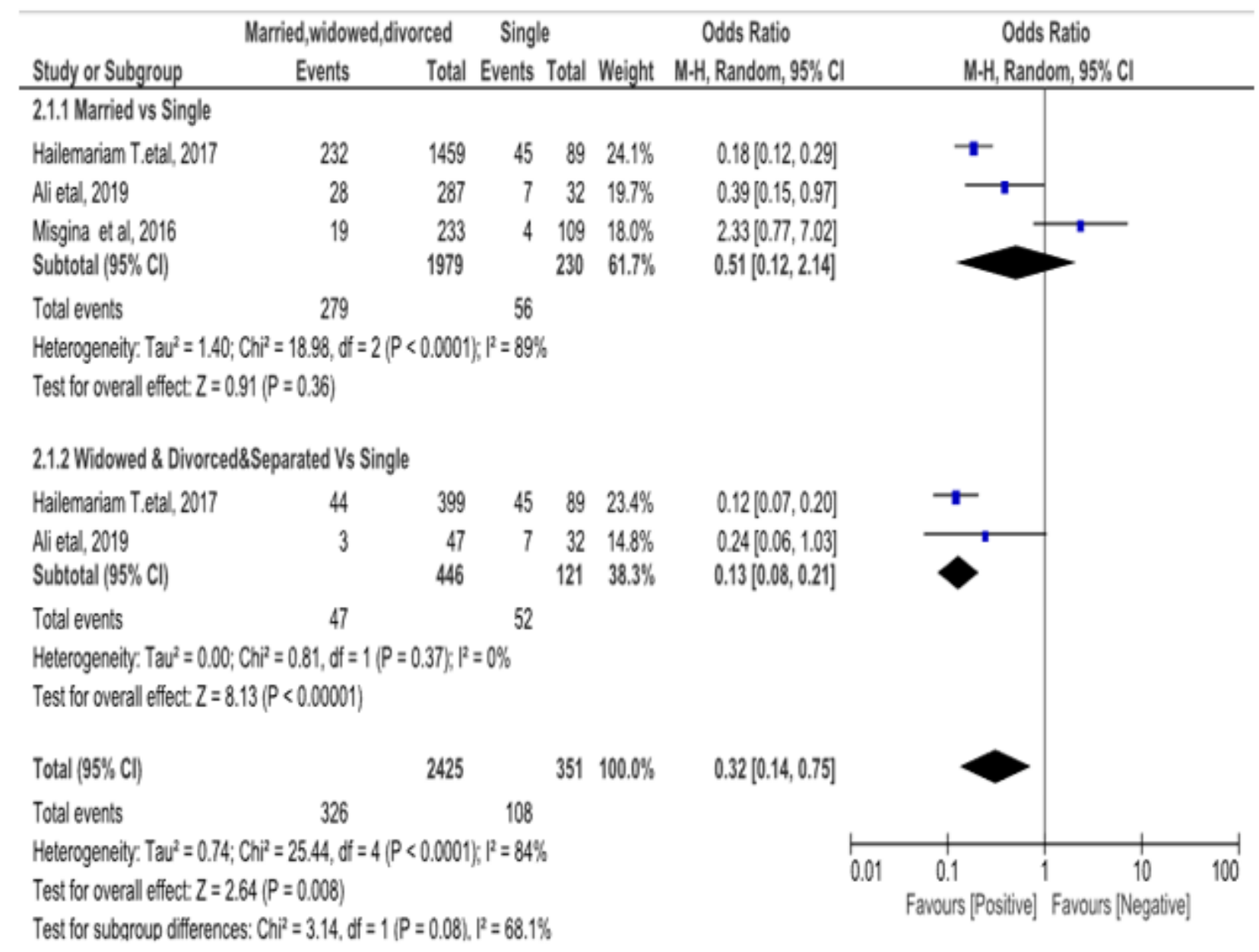

\section{Figure 6}

Forest plot showing the association between marital status and cervical cancer among women in Ethiopia

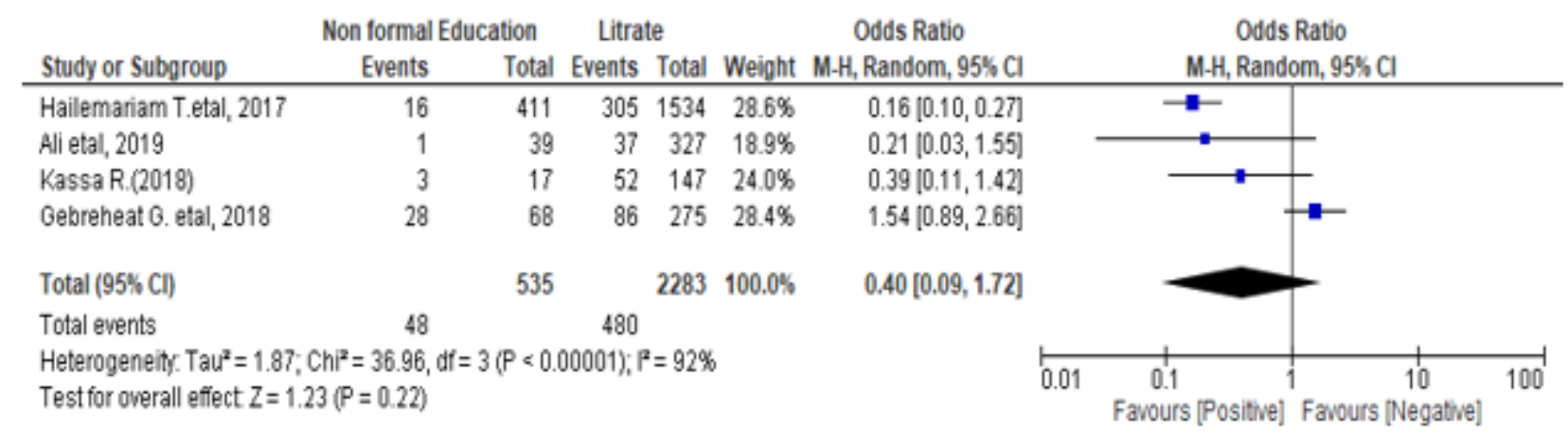

\section{Figure 7}

Forest plot showing the association between educational background and cervical cancer among women in Ethiopia $(n=4)$ 
Unemployed Employed Odds Ratio Odds Ratio

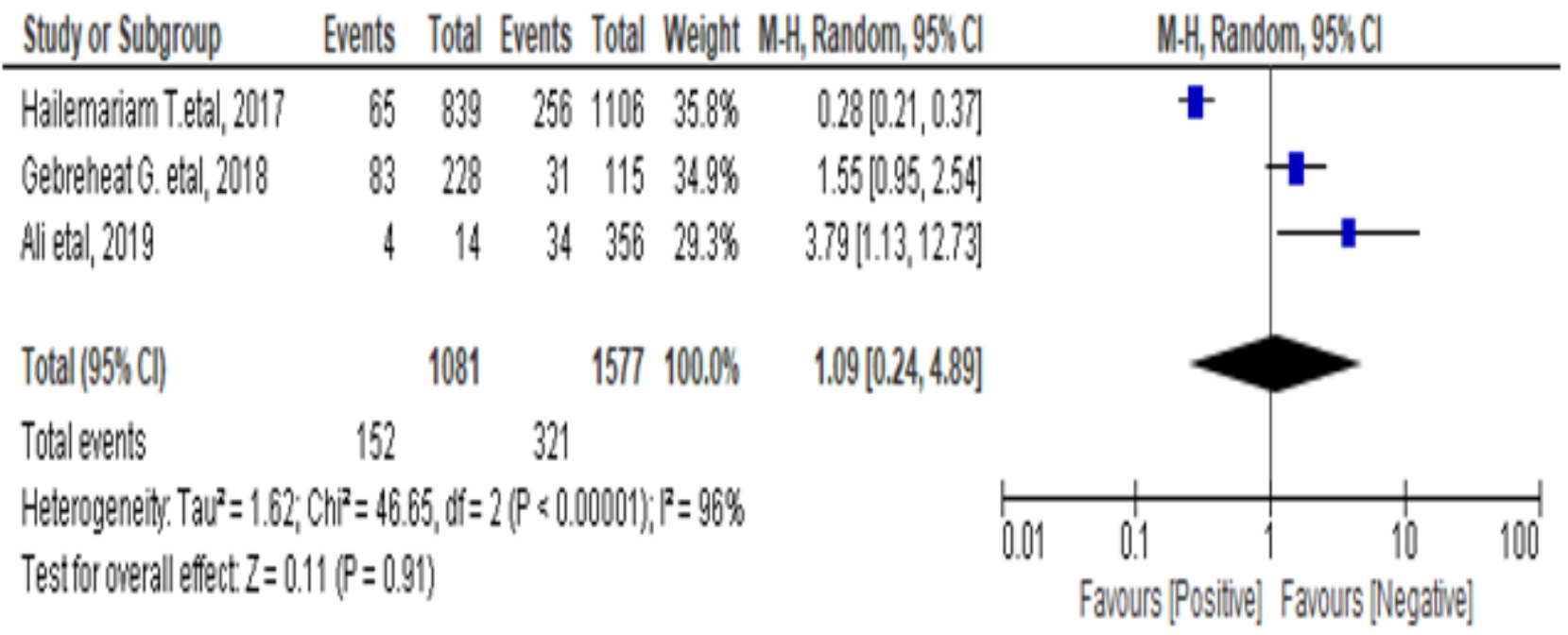

\section{Figure 8}

Forest plot showing the association between occupation and cervical cancer among women in Ethiopia $(n=3)$

Utran Rural OdisRatio Odss Ratio

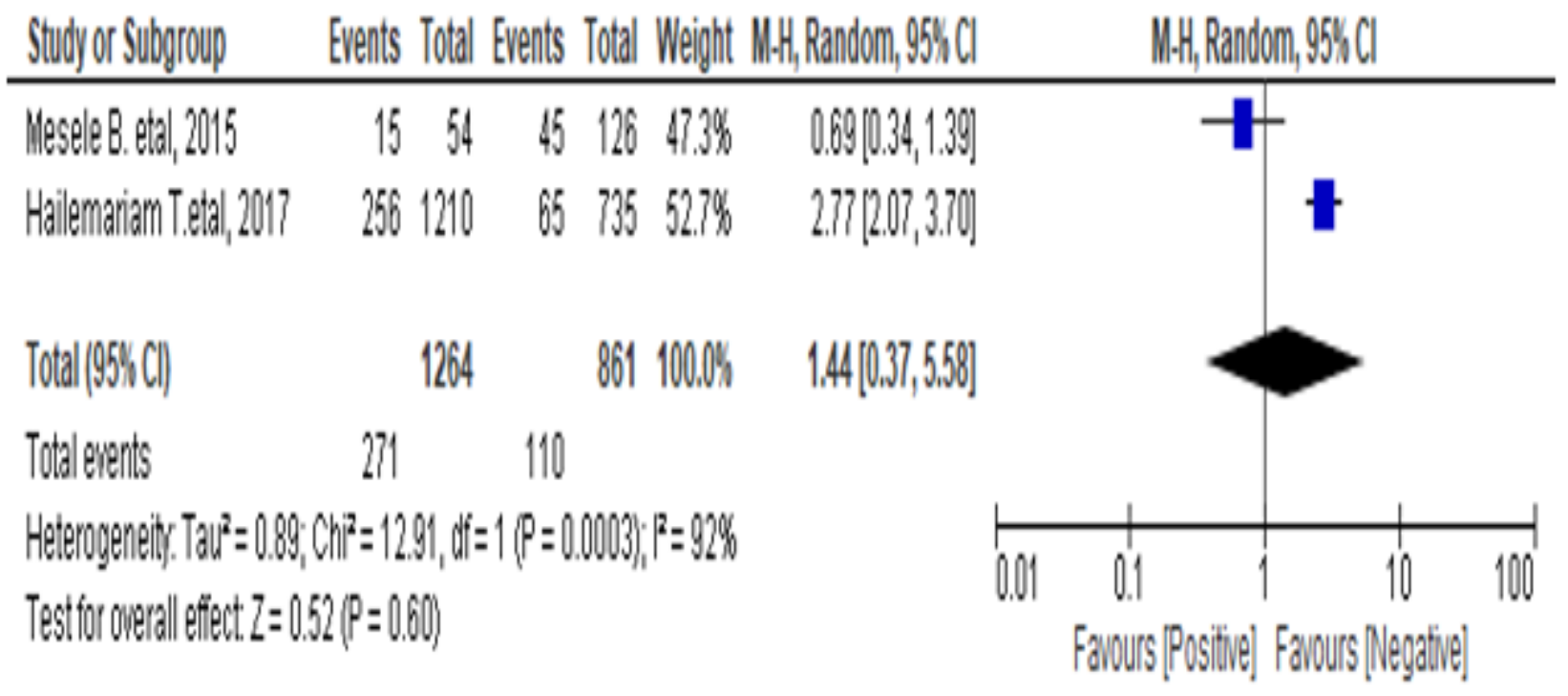

\section{Figure 9}

Forest plot showing the association between residence and cervical cancer among women in Ethiopia $(n=2)$ 
4000Bir $\quad y=$ 1000Bir $\quad$ Odds Ratio Odds Ratio

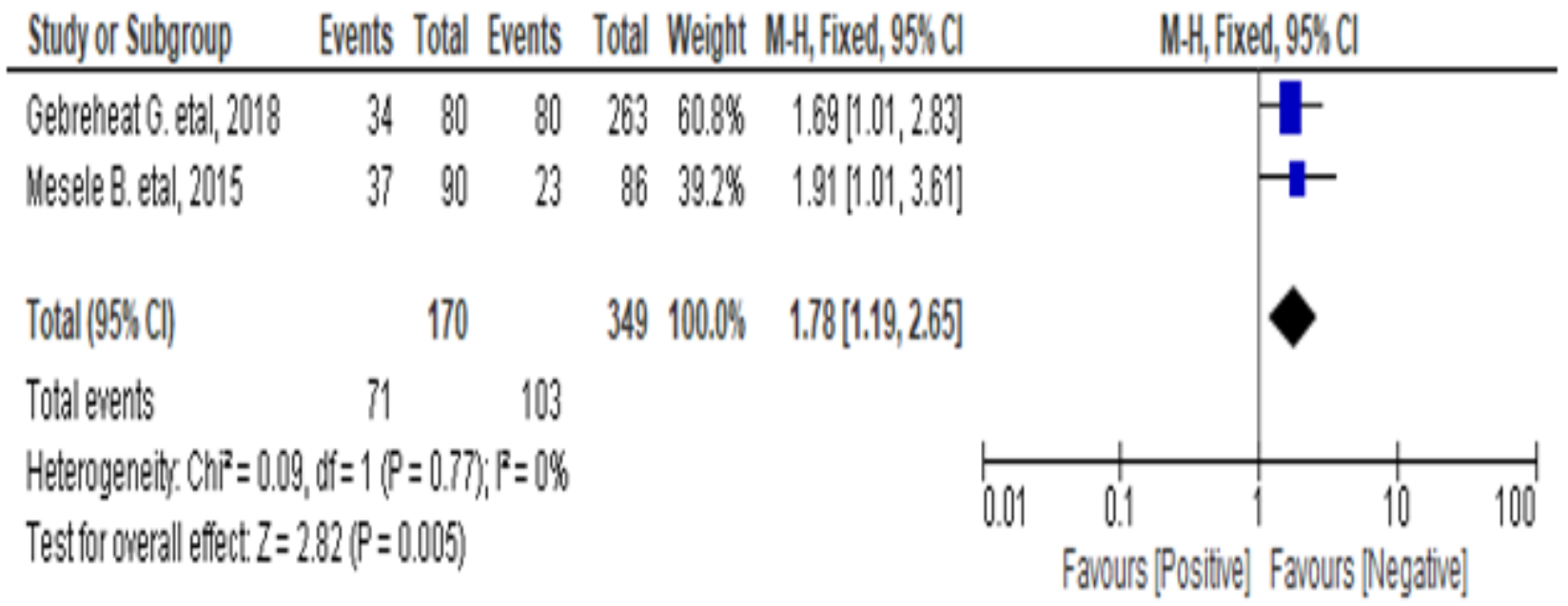

\section{Figure 10}

Forest plot showing the association between income and cervical cancer among women in Ethiopia $(n=2)$

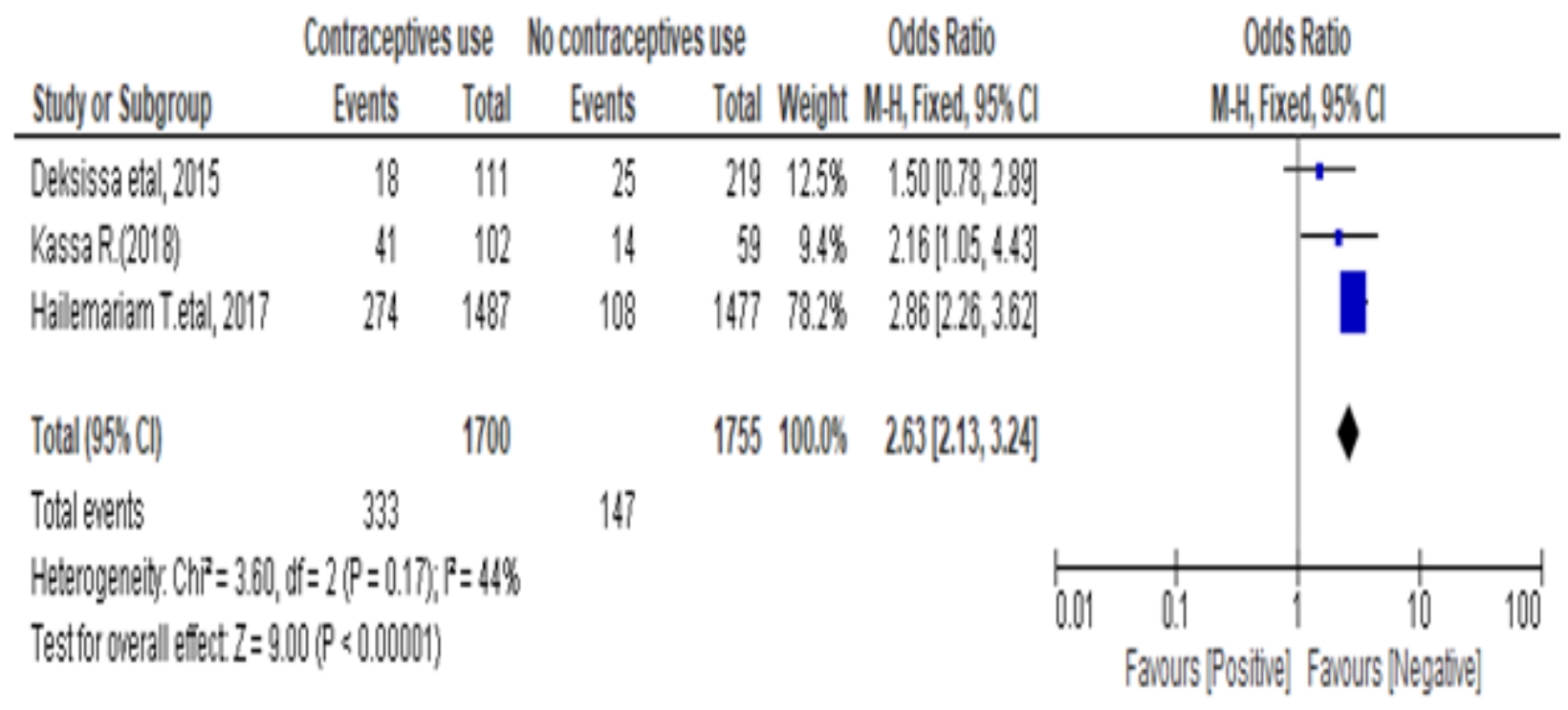

\section{Figure 11}

Forest plot showing the association between contraceptive use and cervical cancer among women in Ethiopia $(n=3)$ 


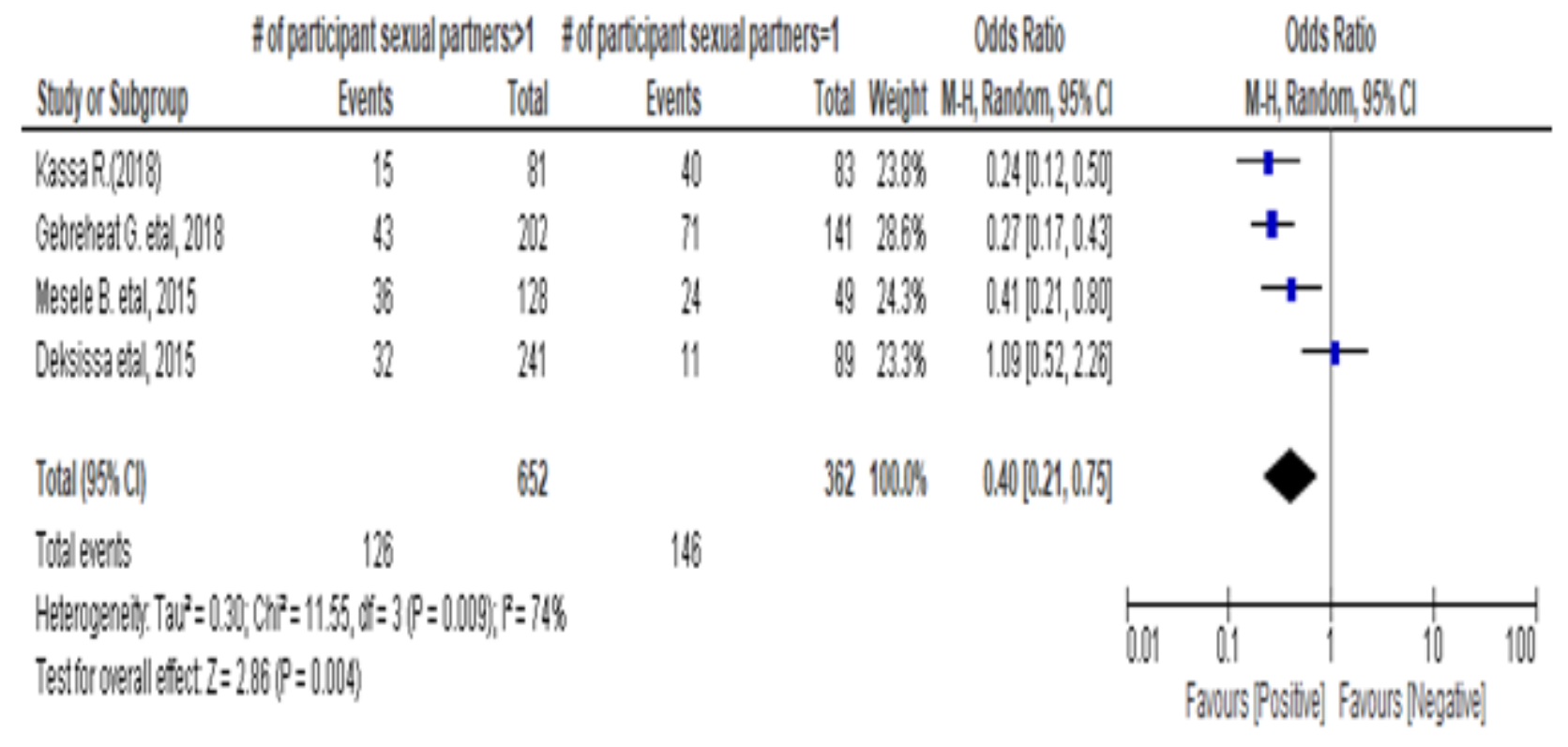

Figure 12

Forest plot showing the association between contraceptive use and cervical cancer among women in Ethiopia $(n=3)$

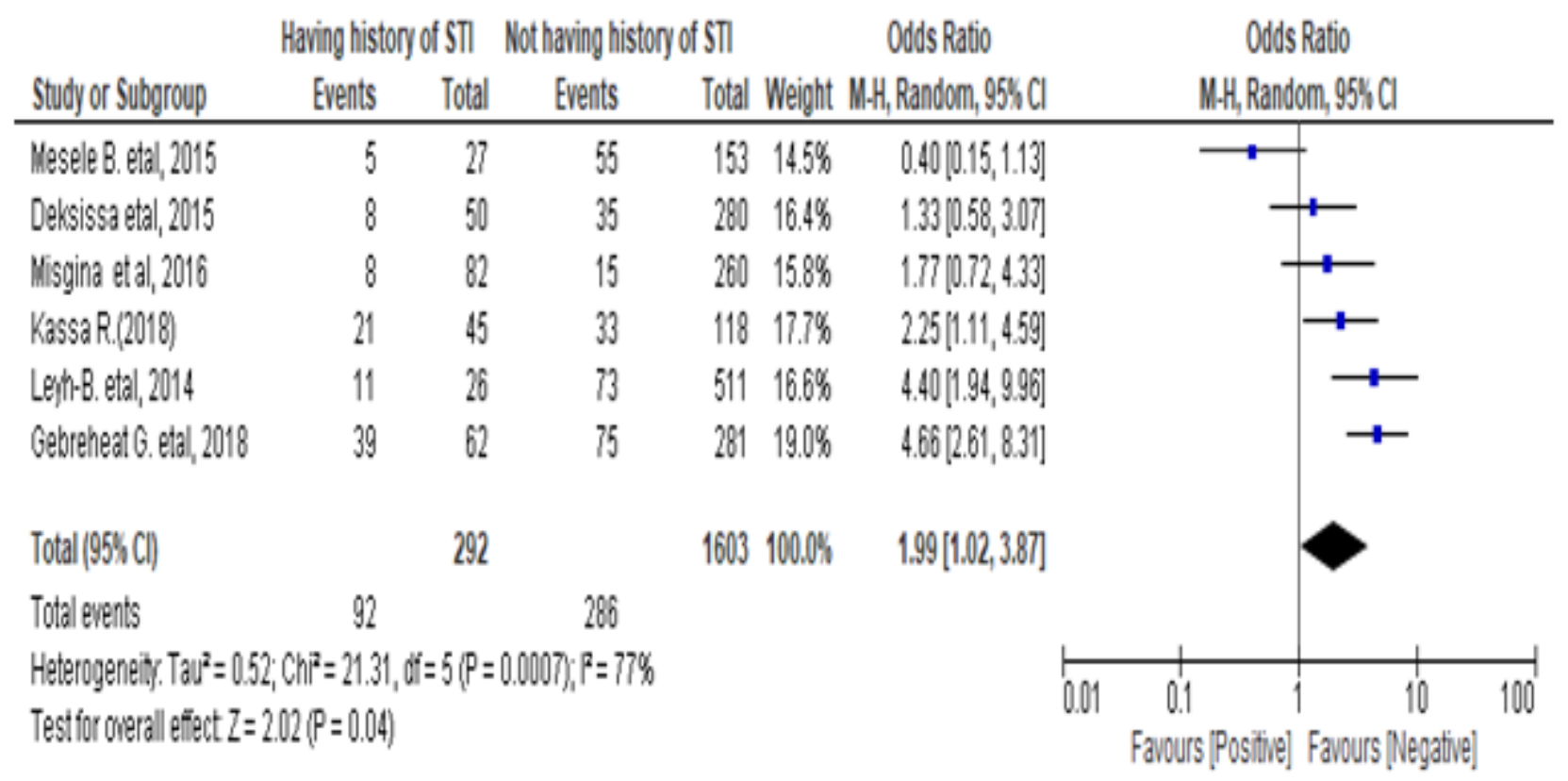

Figure 13

Forest plot showing the association between history of STI and cervical cancer among women in Ethiopia $(n=6)$ 
Misgina et al, 2016

KassaR.(2018)

Deksissa etal, 2015

Getinet M.etal, 2015

Gebreheat G. etal, 2018

Hailemariam T.etal, 2017

Total $(95 \% \mathrm{Cl})$

Total events

Heterogeneity. Taud $]^{2}=0.55 ; \mathrm{Ch}^{2}=28.39, \mathrm{df}=\left.5(\mathrm{P}<0.0001)_{1}\right|^{2}=82 \%$

Test for overall effect $Z=2.23(P=0.03)$
$513 \quad 2839100.0 \% \quad 2.19[1.10,4.35]$

$1.03[0.36,2.92]$

$1.38[0.71,2.66]$

$2.09[1.15,3.77]$

$2.24[1.38,3.64]$

$8.31[4.98,13.87]$

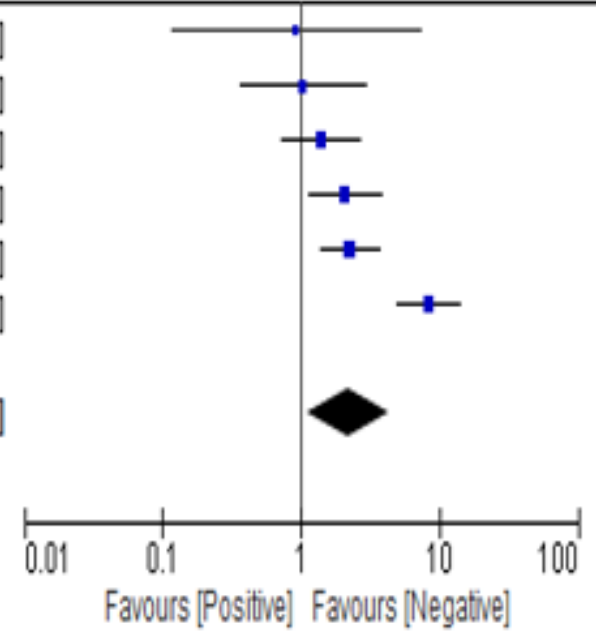

\section{Figure 14}

Forest plot showing the association between HIV Status and cervical cancer among women in Ethiopia $(n=6)$

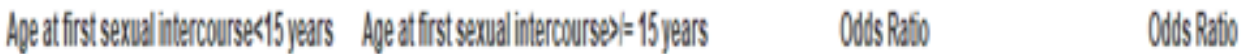

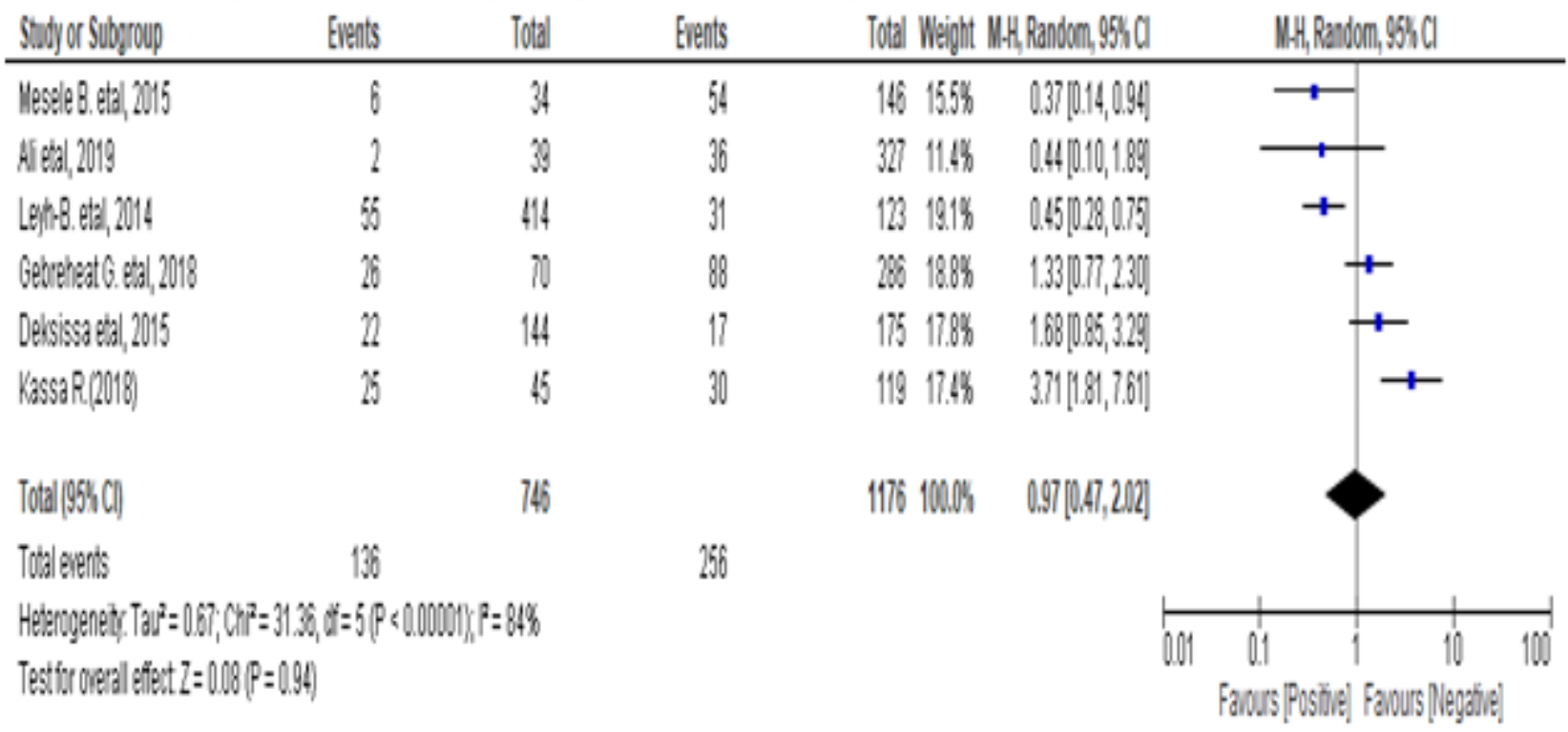

\section{Figure 15}

Forest plot showing the association between age at first sexual intercourse and cervical cancer among women in Ethiopia $(n=6)$ 


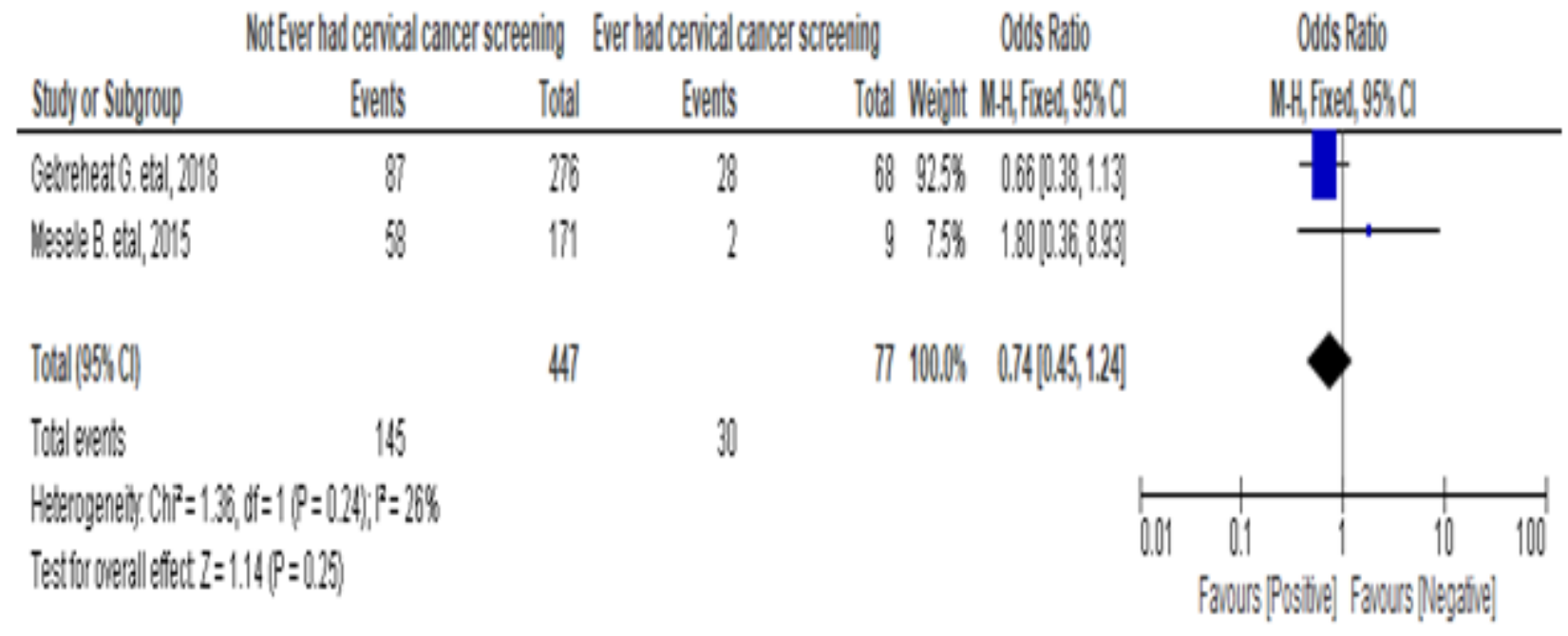

\section{Figure 16}

Forest plot showing the association between ever had cervical cancer screening and cervical cancer among women in Ethiopia $(\mathrm{n}=2)$ 